\title{
SIGLA AND BIBLIOGRAPHY
}

Sigla of all the manuscripts used for the edition, including an editio princeps $(C-M)$ that was apparently based on now lost manuscript
A Athen. Mus. Benaki TA 250 (93), ff. 2r-119v, saec. XVIII (scriba Nicolaus Caratzas) (apographon $\mathbf{U}$ )
B Vat. Barber. gr. 240, saec. XIII exeuntis
C Cantabr. Collegii Trinitatis O.10.33 (1485), ff. 142r-203v, ca. 1623-1625? (scriba socius Patricii Junii)
C-M editio princeps: Theophilus Corydalleus (et Nicolaus Metaxas) Пepi

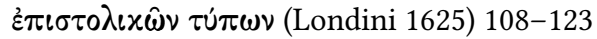
D Paris. gr. 1277, ff. 244r-271v, saec. XII exeuntis (?)
E Scorial. $\Upsilon$ I 9 (248), ca. a. 1540 - a. 1546 (Diego Hurtado de Mendoza patronus) (apographon $\mathbf{M})$
F Laur. Acqu. 39, saec. XVI (prima pars; in circulo Georgii Calybae [ $†$ post a. 1544])
H Heidelb. Palat. gr. 356, saec. XIII exeuntis
K Vat. gr. 712, ff. 49r-200v, saec. XII (medii?)
L Laur. Plut. gr. 57.40, saec. XII (primum quartarium?), cum paucis scholiis et correctionibus
M Marc. gr. Z. 524, saec. XIII exeuntis (ca. a. 1280 - a. 1290?)
O Oxon. Barocc. gr. 131, saec. XIII, altera pars (ca. a. 1260 - a. 1280? in circulo Manuelis Holoboli?)
P Paris. gr. 1182, saec. XII exeuntis (Eustathius Thessalonicensis patronus?), cum paucis scholiis et correctionibus
U Vat. gr. 1912, ff. 143r-187v, saec. XII (primum quartarium?), cum scholiis, additionibus, et correctionibus Leonis Allatii
V Vat. gr. 672, saec. XIII exeuntis (ante a. 1293)
Y Petropol. gr. 250 (454), saec. XIII medii (Nicandrus scriba; Isaac Mesopotamites patronus)
$\mathbf{a}^{\mathbf{1}} \quad$ Athen. Bibl. Nat. 1896, saec. XVI exeuntis vel XVII ineuntis
$\mathbf{a}^{2} \quad$ Athen. Bibl. Nat. 2429, saec. XIV, prima pars
$\mathbf{a}^{3} \quad$ Athen., Bibl. Nat., Metochion Panagiou Taphou 363, f. Iv, saec. XVIII (scriba Nicolaus Caratzas) (apographon A?)
$\mathbf{a}^{4} \quad$ Athous Batopedii 207, saec. XIX (post a. 1839), ff. 10r-11v (apogra- phon $\mathbf{T a f}^{2}$ )
$\mathbf{a}^{5} \quad$ Athous Dionysii 274 (olim 3808 Lampros), saec. XVI
$\mathbf{a}^{6} \quad$ Athous Iberon 189 (olim 4309 Lampros), ff. 369r-370v, saec. XIV medii (apographon Y?)
$\mathbf{a}^{7} \quad$ Athous Laurae M 30 (olim 1721 Eustratiades), saec. XVII/XVIII (apographon $\mathbf{C}-\mathbf{M})$
$\mathbf{a}^{8} \quad$ Athous Pantocratoris 120 (olim 1154 Lampros), ff. 53r-84v, saec. XV 
$\mathbf{a}^{9} \quad$ Alexandr. 368, saec. XVII (apographon C-M)

$\mathbf{b}^{\mathbf{1}} \quad$ Berol. gr. 76 (Phillipps 1480), saec. XV

b $^{2} \quad$ Bucur. gr. 587 (Litzica 737), saec. XVIII (apographon C-M)

c $^{1} \quad$ Cantabr. Uni. Lib. Gg.I.2, saec. XV

c $^{2} \quad$ Constantinop. Panag. Kamariotissae 64, saec. XIII exeuntis

c $^{3} \quad$ Constantinop. Panag. Kamariotissae 157, ff. 93r-145v, 221r-244v, et 311r-326v, saec. XIV medii

$\mathbf{e}^{\mathbf{1}} \quad$ Scorial. $\Phi$ III 1 (220), saec. XVI, ca. a. 1540 - a. 1550 (Georgius Corinthius patronus) (apographon $\mathbf{E})$

$\mathbf{e}^{2} \quad$ Ambros. M 84 sup, saec. XVI, medii (apographon $\mathbf{e}^{\mathbf{1}}$ )

f Laur. San Marco 303, ff. 90v, 138r, et 209v-210r, saec. XIV (Ioannes Asanes scriba?)

i Bucur. gr. 508 (Litzica 594), saec. XIII exeuntis, pp. 230, 237-238, et 295-296 (in collectione epistolarum Hierothei monachi)

$\mathbf{m}^{\mathbf{1}} \quad$ Marc. gr. Z. 445 , saec. XIV, prima pars

$\mathbf{m}^{2} \quad$ Monac. gr. 98, ff. 255A-444v, ca. a. 1550 (apographon $\mathbf{e}^{\mathbf{1}}$ )

$\mathbf{m}^{3} \quad$ Mosq. Vlad. 395 (= Bibl. Synod. gr. 303), ff. 309v-319v, saec. XVI

$\mathbf{m}^{4} \quad$ Mosq. Vlad. 449 (= Bibl. Synod. gr. 239), ff. 223r-233v, saec. XIV (apographon $\mathbf{P}$ )

$\mathbf{m}^{\mathbf{5}} \quad$ Marc. gr. XI.22, saec. XIII, altera pars

$\mathbf{n}^{\mathbf{1}}$ Laur. Plut. gr. 59.12, saec. XIII medii (Nicandrus scriba; Isaac Mesopotamites patronus)

$\mathbf{n}^{2} \quad$ Neap. Bibl. Nat. II C 33, ff. 278r-530v, ca. a. 1490 - a. 1495 (Ioannes Xerokalitos scriba, apographon $\mathbf{~}^{\mathbf{1}}$ )

$\mathbf{o}^{1} \quad$ Oxon. Bodl. Arch. Seld. supra 17, saec. XV

$\mathbf{p}^{\mathbf{1}} \quad$ Paris. suppl. gr. 593, saec. XVII (François Combefis scriba, apographon $\mathbf{P}$ )

$\mathbf{p}^{2} \quad$ Paris. suppl. gr. 1334, saec. XVIII (Isaac scriba) (apographon C-M)

$\mathbf{p}^{3} \quad$ Paris. suppl. gr. 249, a. 1568-1569 (Petrus Morellius scriba)

r Vallicell. Allatius 63, fasc. 6 (apographon V) et fasc. 20 (apographon B, $\mathbf{H}$, et $\mathbf{v}^{\mathbf{4}}$ )

t Thessalon. Bibl. Univ. 96, saec. XVIII (apographon C-M)

$\mathbf{v}^{1} \quad$ Vat. gr. 306, ff. 1r-128r, saec. XIII exeuntis vel XIV ineuntis, ff. $89 \mathrm{r}-96 \mathrm{v}$ (in collectione epistolarum selectarum)

$\mathbf{v}^{2} \quad$ Vat. gr. 483, saec. XIII exeuntis vel XIV ineuntis

$\mathbf{v}^{3} \quad$ Vat. gr. 1891, saec. XIII exeuntis vel XIV ineuntis (Thessalonicae; in circulo Ioannis Pediasimi?), f. 41r-v (in collectione epistolarum Ioannis Apocauci)

$\mathbf{v}^{4} \quad$ Vat. gr. 1900, saec. XVII exeuntis (Laurentius Portius scriba, apographon $\mathbf{V}$ )

$\mathbf{w}^{\mathbf{1}}$ Vind. Theol. gr. 160, ff. 210v-212v, saec. XIII, altera pars

$\mathbf{w}^{2} \quad$ Vind. Phil. gr. 342, saec. XI (altera pars?)

$\mathbf{w}^{3} \quad$ Vind. Phil. gr. 321, saec. XIII, altera pars 


\section{Additional sigla and abbreviations}

$\begin{array}{ll}\langle\rangle & \text { addenda } \\ \{\} & \text { delenda } \\ {[]} & \text { supplenda in lacuna codicis } \\ {[\ldots]} & \text { lacuna codicis vel litterae non leguntur } \\ & \\ \dagger & \begin{array}{l}\text { locus corruptus } \\ \text { * }\end{array} \\ & \text { epistulae aliorum auctorum in collectione Pselli preservatae }\end{array}$

$\begin{array}{ll}\begin{array}{l}\text { ante corr. } \\ \text { add. }\end{array} & \begin{array}{l}\text { ante correctionem } \\ \text { cf. }\end{array} \\ \text { corr. } & \text { confidit (addiderunt) } \\ \text { e.g. } & \text { correxit (correxerunt) } \\ \text { in marg. } & \text { exempli gratia } \\ \text { l. } & \text { in margine } \\ \text { om. } & \text { omittit (omittunt) } \\ \text { post corr. } & \text { post correctionem } \\ \text { prop. } & \text { proposuit (proposuerunt) } \\ \text { scil. } & \text { scilicet } \\ \text { suppl. } & \text { supplevit }\end{array}$

Abbreviations and sigla of all editions, articles pertaining to the formation of the edited text, and commentators (attested in the manuscripts; present in earlier editions; and those who offered suggestions to the present work)

II the present edition (Michaelis Pselli Epistulae, vols. I and II).

Ag1 Agati, M. L. "Tre epistole inedite di Michele Psello", Siculorum Gymnasium 33 (1980) 909-916.

$\mathbf{A g}^{2} \quad$ Agati, M. L. "Due epistole di Psello ad un monaco del monte Olimpo", in Studi albanologici, balcanici, bizantini e orientali in onore di G. Valentini, S. J. (Florence 1986) 177-190.

Alb Albini, U. "Psello epist. 124 Sathas", Studi Italiani di Filologia Classica 5 (1987) 212-213.

All Leo Allatius

All ${ }^{1} \quad$ Allatius, L. "De graecorum hodie quorundam opinationibus epistola”, in De templis Graecorum recentioribus, ad Ioannem Morinum - De Narthece ecclesiae veteris, ad Gasparem de Simeonibus; nec non de Graecorum hodie quorun- 
dam opinationibus, ad Paulum Zacchiam (Cologne 1645) 113-184: 177-178.

Ana ${ }^{1} \quad$ Anastasi, R. "Sulla fine dell'epistola di Psello a Giovanni Xifilino”, Byzantion 58 (1988) 455-456.

Ana $^{2}$

Anastasi, R. "Psello e le Kinolexie", Studi di filologia bizantina 4, Quademi del Siculorum Gymnasium 16 (Catania 1988) 55-79.

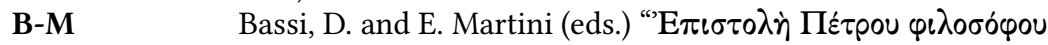

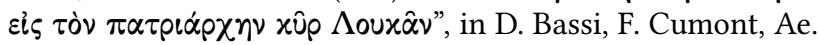
Martini, and A. Olivieri (eds.) Catalogus codicum astrologorum graecorum IV. Codices italicos: praeter florentinos, venetos, mediolanenses, romanos (Brussels 1903) 156-158.

Boi Boissonade, J. F. (ed.) Michael Psellus de operatione daemonum cum notis Gaulmini. Accedunt inedita opuscula Pselli (Nuremberg 1838 = Amsterdam 1964) 117-120 (Epist. 10), 170-188 (Epist. 1-9).

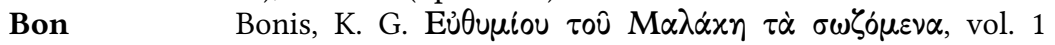
(Athens 1937) 45.

Can Canart, P. "Les "morceaux choisis» de Psellos du Vaticanus Graecus 712”, Bollettino dei Classici 27 (2006) 3-14, at 5-14.

Can $^{2} \quad$ Canart, P. "Nouveaux inédits de Michel Psellos", Revue des études byzantines 25 (1967) 43-60.

Cau Caudano, A.-L. "'Le ciel a la forme d'un cube ou a été dressé comme une peau': Pierre le Philosophe ou l'orthodoxie du savoir astronomique sous Manuel Ier Comnène", Byzantion 81 (2011) 19-73, at 48-51.

Cre Creuzer, F. (ed.) "Michaelis Pselli epistolae hucusque ineditae”, on f. T. Friedemann and J. D. G. Seebode, Miscellanea maximam partem critica II (Wittenberg 1823) 601-623.

Cris ${ }^{1}$ Criscuolo U. (ed.) Michele Psello, Epistola a Giovanni Xifilino (Naples 1990).

Cris $^{2} \quad$ Criscuolo, U. (ed.) Michele Psello, Epistola a Michele Cerulario (Naples 1990).

Cris $^{3} \quad$ Criscuolo, U. "Sui rapporti tra Michele Psello e Giovanni Xifilino (ep. 191 Kurtz-Drexl)”, Atti della Accademia Pontaniana 24 (1975) 121-128.

Cris $^{4} \quad$ Criscuolo, U. "Note filologiche”, Bollettino della Badia greca di Grottaferrata 30 (1976) 59-63.

Dar Darrouzès, J. Épistoliers byzantins du Xe siècle (Paris 1960) 192-193.

Diam Diamantopoulos, A. N. review of K-D in 'E $\pi \varepsilon \tau \eta p i s ~ \tau \hat{\eta} \varsigma$

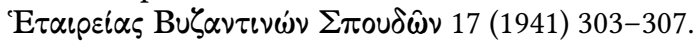

Franz Dölger corrections to K-D

G

Gautier, P. "Quelques lettres de Psellos inédites ou déjà éditées”, Revue des Études Byzantines 44 (1986) 111-197. 
$\mathbf{G}^{2} \quad$ Gautier, P. "Collections inconnues ou peu connues de textes pselliens”, Rivista di Studi Bizantini e Slavi 1 (1981) 39-69.

G $^{3} \quad$ Gautier, P. "Un recueil de lettres faussement attribué à Michel Psellos”, Revue des Études Byzantines 35 (1977) 99-106.

$\mathbf{G}^{4} \quad$ Gautier P. "Eloge funèbre de Nicolas de la Belle Source par Ciro Giacomelli

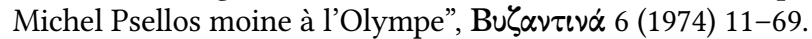

Gui Guida, A. "Proposte di Correzioni al Testo dei Nuovi 'Morceaux Choisis' di Michele Psello”, Byzantinische Zeitschrift 103 (2010) 43-48.

H-M Hase, C. B. and E. Miller (eds.) Recueil des Historiens des Croisades, Historiens Grecs I (Paris 1875).

Jou $^{1} \quad$ Jouanno, C. in Riedinger, J.-C. and C. Jouanno (eds.) Portraits de famille / Michel Psellos; textes traduits et commentés; avec le concours de V. Déroche (Paris 2015) 286-297.

$\mathrm{Jou}^{2}$ Jouanno, C. "Michael Psellos on Rhetoric", in B. Krsmanović, L. Milanović, and B. Pavlović (eds.) Proceeding of the 23rd International Congress of Byzantine Studies Belgrade, 22 - 27 August 2016. Round Tables (Belgrade 2016) 547-551.

Kamb Kambylis, A. "Epiphyllides. Neunzig kritische Bemerkungen zu byzantinischen Prosatexten (mit einigen 'Zugaben')", in Kyklos. Griechisches und Byzantinisches. Rudolf Keydell zum neunzigsten Geburtstag (Berlin and New York 1978) 139-140.

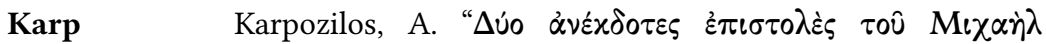

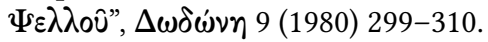

K-D Kurtz, E. and F. Drexl (eds.) Michael Psellus. Scripta minora magnam partem adhuc inedita II, Epistulae (Milan 1941).

Kol Kolovou, F. (ed.) Michaelis Choniatae epistulae (Berlin 2001)

Phaidon Koukoules (p. 289, 1l. 35-45).

corrections to K-D

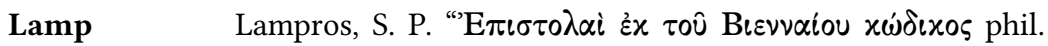

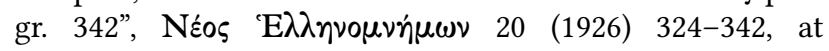
325-326.

Lau Lauxtermann, M. D. "Introduction", in M. Jeffreys and M. D. Lauxtermann (eds.) The Letters of Psellos: Cultural Networks and Historical Realities (Oxford and New York 2017) 3-12.

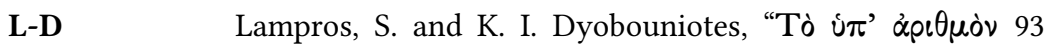

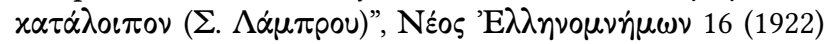
349-392.

Maas corrections to K-D

Mai Mai, A. "De Nicetae paneuphemi epistolis", in Novae patrum bibliothecae VI.2 (Rome 1853) 439-444, at 444. 
Malt

Malt $^{2}$

Malt $^{3}$

Malt $^{4}$

Malt $^{5}$

Charis Messis

Mil

$\mathbf{P}-\mathbf{K}^{\mathbf{1}}$

$\mathbf{P}-\mathbf{K}^{2}$

Pap

$\mathbf{P G}^{1}$

$\mathbf{P G}^{2}$

Pol

Ioannis Polemis

Diether Roderich Reinsch

Rie

Riedinger, J.-C. "Quatre étapes de la vie de Michel Psellos",

Revue des études byzantines 68 (2010) 5-60.

Rue

Maltese, E. V. "Epistole inedite di Michele Psello", Studi Italiani di Filologia Classica 5 (1987) 82-98 and 214-223; 6 (1988) 110-134.

Maltese, E. V. "Il ms. Barocci 131 per l'epistolario di Michele Psello”, Aevum 63 (1989) 186-192, at 187-189.

Maltese, E. V. "Un nuovo testimone dell'epistola di Psello a Giovanni Xifilino (Paris. Gr. 1277)”, Byzantion 57 (1987) 427-432.

Maltese, E. V. "Varia byzantina", in Heptachordos Lyra Humberto Albini oblata (Genoa 1988) 25-37.

Maltese, E. V. "Osservazione critiche sui testo delle epistole di Michele Psello", Jahrbuch der österreichischen Byzantinistik 38 (1988) 247-255.

Miller, E. review of $\mathbf{S}$ in Journal des savants (1876) 249-253 and 261-271.

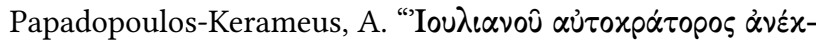

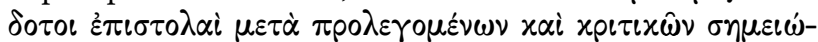

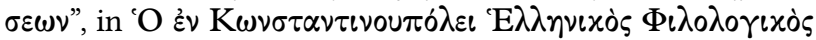

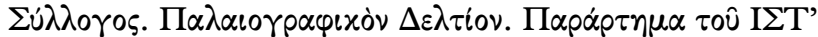

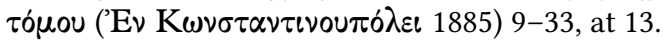

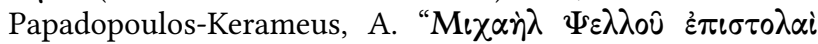

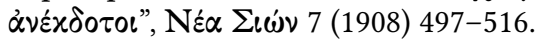

Papaioannou, E. N. "Das Briefcorpus des Michael Psellos. Vorarbeiten zu einer kritischen Neuedition. Mit einem Anhang: Edition eines unbekannten Briefes", Jahrbuch der österreichischen Byzantinistik 48 (1998) 67-117, at 110.

Migne, J.-P. (ed.) Patrologiae Cursus Completus, Series Graeca 122: Georgii Cedreni Compendium Historiarum, etc. (Paris 1889) 1161-1186.

Migne, J.-P. (ed.) Patrologiae Cursus Completus, Series Graeca 136: Eustathii Thessalonicensis Metropolitae Opera, etc. (Paris 1865) 1317-1334.

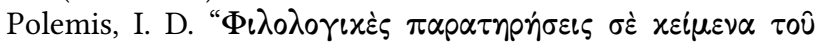

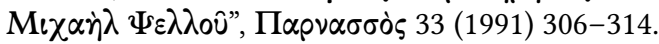

Ruelle, C. É. (ed.) "Lettres sur la musique. Rapports sur une mission littéraire et philologique en Espagne”, Archives des Missions scientifiques et littéraires III 2 (1875) 497-627 = Idem, Études sur l' ancienne musique grecque (Paris 1875) 120-127, at 120-121. 
$\mathbf{S}$

$\mathbf{S}^{2}$

Sni

Spa

Spy

$\operatorname{Taf}^{1}$

Taf $^{2}$

Wei $^{1}$

$\mathrm{Wei}^{2}$

Wes

Vin

V-V De Vries-Van der Velden, E. "Psellos, Romain IV Diogénès et

Z-L Zajcev, A. I. and J. N. Ljubarskij "Dva pis'ma Michaila Psella”, Byzantinoslavica 39 (1978) 24-28.

Bibliography of works cited in the introduction and the apparatus fontium, i.e. apparatus historicus

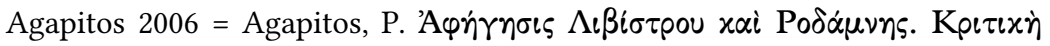

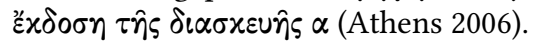

Agapitos, Hult, and Smith 1996 = Agapitos, P. A., K. Hult, and O. L. Smith, Theodoros Metochites on philosophic irony and Greek history: 
Miscellanea 8 and 93, edited with an introduction, translation, and notes (Nicosia and Göteborg 1996).

Agapitos and Polemis 2002 = Agapitos, P. A. and I. D. Polemis, "Проร $\mu \iota \alpha$

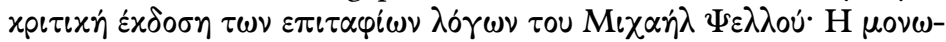

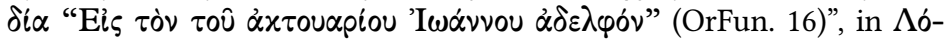

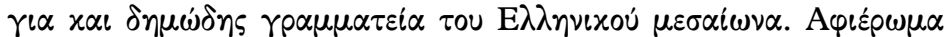

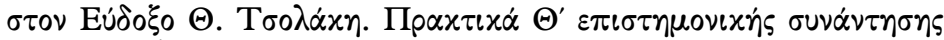
(11-13 Maíou 2000) (Thessalonike 2002) 139-160.

Anastasi 1976 = Anastasi, R. "Sulla tradizione manoscritta delle opere di Psello", in Studi di filologia bizantina (Catania 1976).

Andrés 1965 = de Andrés, G. Catálogo de los Códices Griegos de la real Biblioteca de El Escorial. t. II: Códices 179-420 (Madrid 1965).

Astruc and Concasty $1960=$ Astruc, C. and M. Concasty, Bibliothèque nationale. Catalogue des manuscrits grecs. Troisième partie: Le Supplément grec, Tome III, numéros 901-1371 (Paris 1960).

Astruc-Morize 1983 = Astruc-Morize, G. "Un nouveau "Codex Mésopotamitou”: Le Parisinus Graecus 194 A”, Scriptorium 37 (1983) 105-109.

Atsalos 1971 = Atsalos, B. La terminologie du livre-manuscrit à l'époque byzantine: première partie, termes désignant le livre-manuscrit et l'ecriture (Thessalonike 1971).

Aujac 1975 = Aujac, G. "Michel Psellos et Denys d' Halicarnasse: Le traité sur la composition des éléments du langage”, Revue des Études Byzantines 33 (1975) 257-275.

Bake, J. 1849 = Bake, J. Apsinis et Longini Rhetorica (Oxford 1849).

Barber and Papaioannou 2017 = Barber, C. and S. Papaioannou (eds.) Michael Psellos on Literature and Art: A Byzantine Perspective on Aesthetics (Notre Dame, Ind. 2017).

Beck 1959 = Beck, H. G. Kirche und theologische Literatur im Byzantinischen Reich (Munich 1959).

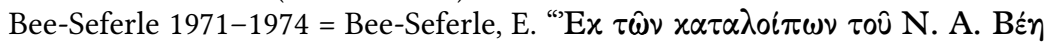

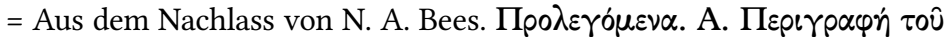

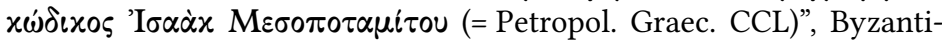
nisch-Neugriechische Jahrbücher 21 (1971-1974) 7-53.

Bernabò and Magnelli 2011 = Bernabò, M. and E. Magnelli "Il codice Laurenziano plut. 32.52 e l'iconografia bizantina dei carmina figurata", Bizantinistica: Rivista di Studi Bizantini e Slavi 2nd ser. 13 (2011) 189-232.

Bernard 2014 = Bernard, F. Writing and Reading Byzantine Secular Poetry, 1025-1081 (Oxford and New York 2014).

Bianchi 2015 = Bianchi, E. Fettaugen-Mode e Beta-gamma Stil: nuove ricerche e una diversa ipotesi interpretativa ( $\mathrm{PhD}$ thesis; Rome 2015).

Bianconi 2004 = Bianconi, D. "Libri e mani. Sulla formazione di alcune miscellanee dell' era dei Paleologi”, in E. Crisci and O. Pecere (eds.) Il codice miscellaneo: tipologie e funzioni: atti del Convegno internazionale, Cassino, 14-17 maggio 2003 (Cassino 2004) 311-363. 
Bianconi 2005 = Bianconi, D. Tessalonica nell'età dei Paleologi: le pratiche intellettuali nel riflesso della cultura scritta (Paris 2005).

Bianconi 2010 = Bianconi, D. "Età Comnena e cultura scritta: Materiali e considerazioni alle origini di una ricerca”, in A. Bravo García and I. Pérez Martín (eds. with the assist. of J. Signes Codoñer), The Legacy of Bernard de Montfaucon: Three Hundred Years of Studies on Greek Handwriting. Proceedings of the Seventh International Colloquium of Greek Palaeography (Madrid - Salamanca, 15-20 September 2008) (Turnhout 2010) 75-96 and 707-718.

Bianconi 2011 = Bianconi, D. "«Piccolo assaggio di abbondante fragranza». Giovanni Mauropode e il Vat. gr. 676”, Jahrbuch der österreichischen Byzantinistik 61 (2011) 89-103.

Bidez 1928 = Bidez, J. (ed.) "Michel Psellus, Epître sur la Chrysopée. Opuscules et extraits sur l'alchimie, la météorologie et la démonologie," Catalogue des Manuscrits alchémiques grecs 6 (1928) 26-42.

Böhlig 1956 = Böhlig, G. R. Untersuchungen zum rhetorischen Sprachgebrauch der Byzantiner mit besonderer Berücksichtigung der Schriften des Michael Psellos (Berlin 1956).

Boll $1908=$ Boll, F. Catalogus codicum astrologorum graecorum VII: Codices Germanicos (Brussels 1908).

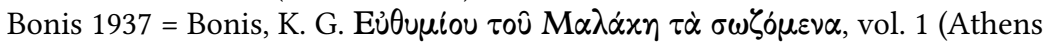
1937).

Bydén 2012 = Bydén, B. "Imprimatur? Unconventional Punctuation and Diacritics in Manuscripts of Medieval Greek Philosophical Works”, in A. Bucossi and E. Kihlman (eds.) Ars Edendi. Lecture Series, Vol. II. (Stockholm 2012) 155-172.

Canart 1967 = Canart, P. "Nouveaux inédits de Michel Psellos", Revue des études byzantines 25 (1967) 43-60.

Canart 1970 = Canart, P. Codices Vaticani Graeci. Codices 1745-1962, vol. 1 (Vatican 1970).

Canart 1973 = Canart, P. Codices Vaticani Graeci. Codices 1745-1962, vol. 2, Introductio addenda indices (Vatican 1973).

Canart 1979 = Canart, P. Les Vaticani Graeci, 1487-1962: notes et documents pour l'histoire d'un fonds de manuscrits de la Bibliothéque vaticane (Vatican 1979).

Caudano 2011 = Caudano, A.-L. "'Le ciel a la forme d'un cube ou a été dressé comme une peau': Pierre le Philosophe ou l'orthodoxie du savoir astronomique sous Manuel Ier Comnène”, Byzantion 81 (2011) 19-73.

Caudano 2015 = Caudano, A.-L. "Cosmologies et cosmographies variées dans les manuscrits byzantins tardifs”, Byzantion 85 (2015) 1-25.

Cavallo 2000 = Cavallo, G. "Scritture informali, cambio grafico e pratiche librarie a Bisanzio tra i secoli XI e XII”, in G. Prato (ed.) I manoscritti greci tra riflessione e dibattito: atti del V Colloquio internazionale di paleografia greca: Cremona, 4-10 ottobre 1998 (Florence 2000) vol. 1:219-238 and 3:151-178. 


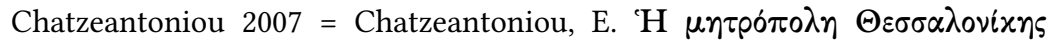

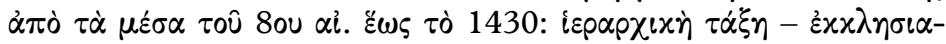

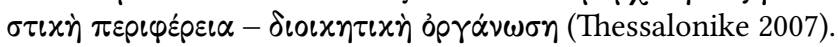

Cheynet I / II = Cheynet, J.-Cl. La société Byzantine. L'apport des sceaux. vols. I-II (Paris 2008).

Cheynet $1990=$ Cheynet, J.-Cl. Pouvoir et contestations à Byzance (963-1210) (Paris 1990).

Cheynet 1999 = Cheynet, J.-Cl. "L'Asie Mineure d'après la correspondance de Psellos”, Byzantinische Forschungen 25 (1999) 233-241.

Cheynet 2013 = Cheynet, J.-Cl. "Michel Psellos et Antioche", Zbornik radova Vizantoloskog instituta 60 (2013) 411-422.

Cheynet $2017=$ Cheynet, J-Cl. "L'administration provinciale dans le correspondance de Michel Psellos", in M. D. Lauxtermann and M. Whittow (eds.) Byzantium in the Eleventh Century. Being in Between, Papers from the 45th Spring Symposium of Byzantine Studies, Exeter College, Oxford, 24-26 March 2012 (Abingdon and New York 2017) 45-59.

Crostini 2014a = Crostini, B. "Paul Moore and More Psellos: Still "Wanted" in Byzantium?”, in I. Nilsson and P. Stephenson (eds.) Byzantium Wanted: The Desire and Rejection of an Empire (Uppsala 2014) 175-184.

Crostini 2015b = Crostini, B. "The Teubner Edition of Psellos in the Light of a New Find in MS Trinity College Dublin 373", in Textual Transmission in Byzantium: Between Textual Criticism and Quellenforschung (Turnhout 2014) 263-289.

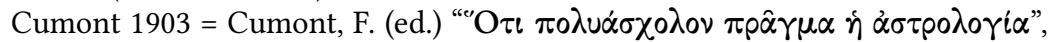
in D. Bassi, F. Cumont, Ae. Martini, and A. Olivieri (eds.) Catalogus codicum astrologorum graecorum IV. Codices italicos: praeter florentinos, venetos, mediolanenses, romanos (Brussels 1903) 96-98.

Cumont 1951 = Cumont, F. (ed.) in S. Weinstock (ed.) Catalogus Codicum Astrologorum Graecorum IX. Codices britannicos. Pars 1. Codices oxonienses (Brussels 1951) 62-74.

Darrouzès 1972 = Darrouzès J. "Un recueil épistolaire du XIIe siècle: Académie Roumaine cod. gr. 508.” Revue des études byzantines 30 (1972) 199-229.

Darrouzès and Westerink 1978 = Darrouzès, J. and L. G. Westerink, Théodore Daphnopatès. Correspondance (Paris 1978).

Davey 1987 = Davey, C. Pioneer for Unity: Metrophanes Kritopoulos (15891639) and Relations between the Orthodox, Roman Catholic and Reformed Churches (London 1987).

Devreesse 1937 = Devreesse, R. Codices Vaticani Graeci. Codices 330-603 (Vatican 1937).

Devreesse $1950=$ Devreesse, R. Codices Vaticani Graeci. Codices 604-866 (Vatican 1950).

De Vries-Van der Velden 1996 = De Vries-Van der Velden, E. "Psellos et son gendre”, Byzantinische Forschungen 23 (1996) 109-149. 
De Vries-Van der Velden 1997 = De Vries-Van der Velden, E. "Psellos, Romain IV Diogénès et Mantzikert”, Byzantinoslavica 58 (1997) 274-310.

De Vries-Van der Velden 1999 = De Vries-Van der Velden, E. "Les amitiés dangereuses: Psellos et Léon Paraspondylos”, Byzantinoslavica 60 (1999) 313-350.

Dölger and Wirth 1995 = Dölger, F. and P. Wirth, Corpus der Griechischen Urkunden des Mittelalters und der neueren Zeit, Reihe A: Regesten, Abteilung I: Regesten der Kaiserurkunden des oströmischen Reiches, 2. Teil: Regesten von 1025-1204 (Munich 1995).

Drexl 1941 = Drexl, F. "Nachträge zur Ausgabe der Psellosbriefe von Kurtz Drexl”, Byzantinische Zeitschrift 41 (1941) 309-310.

Duffy 2001 = Duffy, J. "Bitter Brine and Sweet Fresh Water: The Anatomy of a Metaphor in Psellos", in C. Sode and S. Takács (eds.) Novum Millennium: Studies on Byzantine History and Culture dedicated to Paul Speck, 19 December 1999 (Aldershot 2001) 89-96.

Duffy 2006 = Duffy, J. "Dealing with the Psellos Corpus: From Allatius to Westerink and the Bibliotheca Teubneriana", in C. Barber and D. Jenkins (eds.) Reading Michael Psellos (Leiden 2006) 1-12.

Duyé 1972 = Duyé, N. "Un haut fonctionnaire byzantin du XIe siècle: Basile Malésès", Revue des études byzantines 30 (1972) 167-178.

Fonkič and Poliakov 1993 = Fonkič, B. L. and F. B. Poliakov, Греческие рукописи Московской синодальной библиотеки: палеографические, кодикологические и библиографические дополнения к каталогу архимандрита Владимира (Филантропова) (Moscow 1993).

Fryde 1996 = Fryde, E. B. Greek Manuscripts in the Private Library of the Medici, 1469-1510 (Aberystwyth 1996).

Gautier 1970 = Gautier, P. "La curieuse ascendance de Jean Tzetzes", Revue des études byzantines 28 (1970) 207-220.

Gautier 1974a = Gautier, P. "Le typikon du Christ Sauveur Pantocrator", Revue des études byzantines 32 (1974) 1-145.

Gautier 1974b = Gautier, P. "Eloge funèbre de Nicolas de la Belle Source par

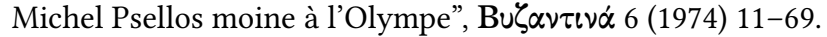

Gautier 1975 = Gautier, P. review of Weiss, Oströmische Beamte, in Revue des études byzantines 33 (1975) 325-330.

Gautier 1976a = Gautier, P. "Un chrysoboulle de confirmation rédigé par Michel Psellos”, Revue des études byzantines 34 (1976) 79-99.

Gautier 1976b = Gautier, P. "Précisions historiques sur le monastère de Ta Narsou”, Revue des études byzantines 34 (1976) 101-110.

Gautier 1977a = Gautier, P. "Un recueil de lettres faussement attribué à Michel Psellos”, Revue des Études Byzantines 35 (1977) 99-106.

Gautier 1977b = Gautier, P. "Michel Psellos et la rhétorique de Longin", Prometheus 3 (1977) 193-203.

Gautier 1978 = Gautier, P. "Monodies inédites de Michel Psellos", Revue des études byzantines 36 (1978) 83-151. 
Gautier 1986a = Gautier, P. "Quelques lettres de Psellos inédites ou déjà éditées”, Revue des Études Byzantines 44 (1986) 111-197.

Gautier 1986b = Gautier, P. "Deux manuscrits pselliens: Le Parisinus Graecus 1182 et le Laurentianus Graecus 57-40”, Revue des Études Byzantines 44 (1986) 45-110.

Giannouli 2014 = Giannouli, A. "Byzantine Punctuation and Orthography. Between Normalisation and Respect of the Manuscripts. Introductory Remarks", COMSt Newsletter 8 (2014) 18-22.

Giannouli and Schiffer 2011 = Giannouli, A. and E. Schiffer (eds.) From Manuscripts to Books. Proceedings of the International Workshop on Textual Criticism and Editorial Practice for Byzantine Texts (Vienna, 10-11 December 2009) (Vienna 2011).

Gioffreda 2013 = Gioffreda, A. "L'Ambrosiano C 279 inf. e il copista Nicandro", Medioevo greco 13 (2013) 127-138.

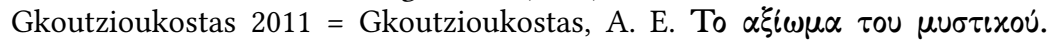

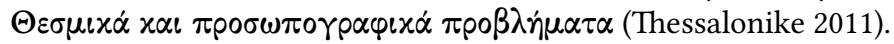

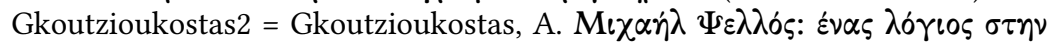

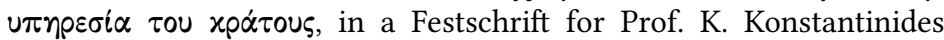
(Ioannina, forthcoming).

Graux 1880 = Graux, C. Essai sur les origines du fonds grec de l'Escurial (Paris 1880).

Grumel 1989 = Grumel, V. Les Regestes des Actes du Patriarcat de Constantinople, t. 1, Les Actes des Patriarches, fasc. 2-3: Les regestes de 715 à 1206, 2e éd. corrigée par. J. Darrouzès (Paris 1989).

Grünbart 2000 = Grünbart, M. "Athanasios Chatzikes und Michael Psellos", Byzantion 70 (2000) 307-308.

Grünbart 2001 = Grünbart, M. Epistularum byzantinarum initia (Hildesheim and New York 2001).

Grünbart 2003 = Grünbart, M. "Anmerkungen zur byzantinischen Briefrhetorik.” in W. Hörandner and M. Grünbart (eds.) L'épistolographie et la poésie épigrammatique: projects actuels et questions de méthodologie: actes de la 16e Table ronde organisée par dans le cadre du XXe Congrès international des Études byzantines, Collège de France - Sorbonne, Paris, 19-25 Août 2001 (Paris 2003) 31-41.

Grünbart 2007 = Grünbart, M. "Nachrichten aus dem Hinterland Konstantinopels: Die Briefsammlung des Mönchs Hierotheos (12. Jahrhundert)", Byzantinische Zeitschrift 100 (2007) 57-70.

Hobson 1999 = Hobson, A. Renaissance Book Collecting: Jean Grolier and Diego Hurtado de Mendoza, their Books and Bindings (Cambridge and New York 1999).

Hunger 1961 = Hunger, H. Katalog der griechischen Handschriften der Österreichischen Nationalbibliothek. 1: Codices historici, codices philosophici et philologici (Vienna 1961). 
Hunger and Kresten 1976 = Hunger, H. and O. Kresten, Katalog der griechischen Handschriften der Österreichischen Nationalbibliothek. Teil 3/1. Codices theologici 1-100 (Vienna 1976).

Hunger, Kresten, and Hannick 1984 = Hunger, H., O. Kresten, and C. Hannick, Katalog der griechischen Handschriften der Österreichischen Nationalbibliothek. Teil 3/2. Codices theologici 101-200 (Vienna 1984).

Hutter 1977 = Hutter, I. Corpus der byzantinischen Miniaturenhandschriften (Stuttgart 1977).

James 1902 = James, M. R. The Western Manuscripts in the Library of Trinity College III (Cambridge 1902).

Janin 1964 = Janin, R. Constantinople byzantine: Développement urbain et répertoire topographique (Paris 1964).

Janin 1969 = Janin, R. La géographie ecclésiastique de l'empire byzantin, I: Le siège de Constantinople et le patriarcat oecuménique, 3: Les églises et les monastères (Paris 1969).

Janin 1975 = Janin, R. Les églises et les monastères des grands centres byzantins (Paris 1975).

Janssens 2002 = Janssens, B. (ed.) Maximi Confessoris Ambigua ad Thomam una cum Epistula secunda ad eundem (Turnhout and Leuven 2002).

Jeffreys 2017a = Jeffreys, M. "Constantine, Nephew of the Patriarch Keroularios, and His Good Friend Michael Psellos”, in M. Jeffreys and M. D. Lauxtermann (eds.) The Letters of Psellos: Cultural Networks and Historical Realities (Oxford and New York 2017) 59-88.

Jeffreys 2017b = Jeffreys, M. "Part II: Summaries of the Letters of Michael Psellos", in M. Jeffreys and M. D. Lauxtermann (eds.) The Letters of Psellos: Cultural Networks and Historical Realities (Oxford and New York 2017) 141-445.

Jeffreys and Lauxtermann 2017 = Jeffreys, M. and M. D. Lauxtermann (eds.) The Letters of Psellos: Cultural Networks and Historical Realities (Oxford and New York 2017).

Kaldellis $2007=$ Kaldellis, A. Hellenism in Byzantium: The Transformations of Greek Identity and the Reception of the Classical Tradition (Cambridge 2007).

Karagiorgou-Charalampakis-Malatras 2016

= Karagiorgou, O., P. Charalampakis, C. Malatras, "State Officials in the Themes of Opsikion, the Anatolikoi and the Kibyrraiotai: New and Recently Revisited Sigillographic Evidence”, Byzantina Symmeikta 26 (2016) 247-308.

Karath. = Karathanasis, D. K. Sprichwörter und sprichwörtliche Redensarten des Altertums in den rhetorischen Schriften des Michael Psellos, des Eustathios und des Michael Choniates sowie in anderen rhetorischen Quellen des XII. Jahrhunderts (Speyer a. Rh. 1936).

Karpozilos 1990 = Karpozilos, A. The Letters of Ioannes Mauropous Metropolitan of Euchaita (Thessalonike 1990). 
Karpozilou 1999 = Karpozilou, M. "The Epistolarion of Theophilos

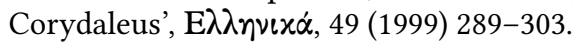

Kazhdan 1993 = Kazhdan, A. P. "Some Problems in the Biography of John Mauropous”, Jahrbuch der österreichischen Byzantinistik 43 (1993) 87-111.

Kazhdan-Ljubarskij 1973 = Kazhdan, A. P. and J. Ljubarskij, "Basile Malésès encore une fois", Byzantinoslavica 34 (1973) 219-220.

K-D I = Kurtz, E. and F. Drexl (eds.) Michael Psellus. Scripta minora magnam partem adhuc inedita I, Orationes et dissertationes (Milan 1936).

Kiapidou 2013 = Kiapidou, E.-S. "Chapters, Epistolary Essays and Epistles. The Case of Michael Glykas' Collection of Ninety-Five Texts in the 12th Century", Parekbolai 3 (2013) 45-64.

Kolia-Dermitzaki 1997 = Kolia-Dermitzaki, A. "Michael VII Doukas, Robert Guiscard and the Byzantine-Norman Marriage Negotiations”, Byzantinoslavica 58 (1997) 251-268.

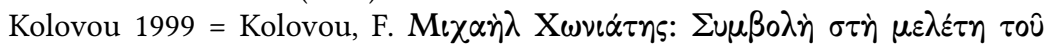

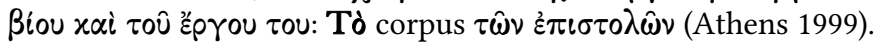

Kolovou 2001 = Kolovou, F. (ed.) Michaelis Choniatae epistulae (Berlin 2001).

Kolovou 2006 = Kolovou, F. (ed.) Die Briefe des Eustathios von Thessalonike (Munich and Leipzig 2006).

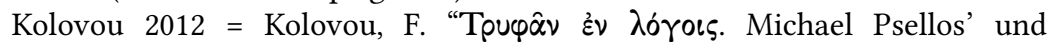
Machetarios' Enkomien auf den Wein im Baroccianus gr. 131”, Buל $\alpha \nu$ $\tau \iota \nu \alpha ́$ 32 (2012) 9-24.

Kouroupou and Géhin 2008 = Kouroupou, M. and P. Géhin, Catalogue des manuscrits conservés dans la Bibliothèque du Patriarcat Oecuménique. Les manuscrits du monastère de la Panaghia de Chalki (Turnhout 2008).

Lambros 1895 = Lambros, S. P. Catalogue of the Greek Manuscripts on Mount Athos, vol. 1. (Cambridge 1895).

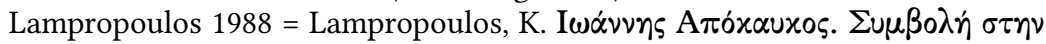

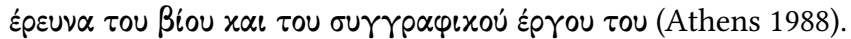

Lappa-Zizica and Rizou-Couroupou 1991 = Lappa-Zizica, E., M. Rizou-

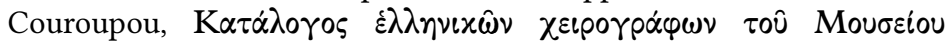

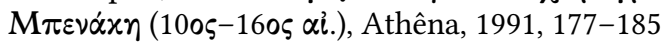

Laurent 1981 = Laurent, V. Le Corpus des sceaux de l'empire byzantin, t. 2 . L'administration centrale (Paris 1981).

Lauxtermann 2012 = Lauxtermann, M. "The Perils of Travel: Mark the Monk and Bodl. E.D. Clarke 15”, on f. Bernard and K. Demoen (eds), Poetry and its Contexts in Eleventh-century Byzantium (Farnham and Burlington 2012) 195-206.

Lauxtermann and Whittow 2017 = Lauxtermann, M. D. and M. Whittow (eds.) Byzantium in the Eleventh Century. Being in Between, Papers from the 45th Spring Symposium of Byzantine Studies, Exeter College, Oxford, 24-26 March 2012 (Abingdon and New York 2017) 45-59. 
LBG = Trapp, E. et a. (ed.) Lexikon zur Byzantinischen Gräzität: besonders des 9.-12. Jahrhunderts (Vienna 1994-2017).

Legrand = Legrand, E. Bibliographie hellénique ou Description raisonnée des ouvrages publiés par des Grecs au dix-septième siècle, vol. 1 (Paris 1894).

Lemerle 1977 = Lemerle, P. Cinq études sur le XIe siècle byzantin (Paris 1977).

Limousin 1999 = Limousin, É. "L'administration byzantine du Péloponnèse (xe-xiie siècles)”, in J. Renard (ed.) Le Péloponnèse, Archéologie et Histoire (Rennes 1999) 298-314.

Litavrin 1969 = Litavrin, G. G. “Три письма Михаила Пселла Катакалону Кекавмену”, Revue des études sud-est européennes 7 (1969) 455-468.

Litzica 1909 = Litzica, C. Catalogul manuscriptelor greceşti din Bibliotheca Academiei Române (Bucharest 1909).

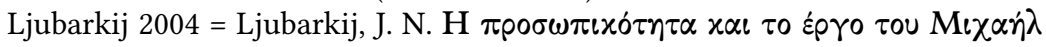

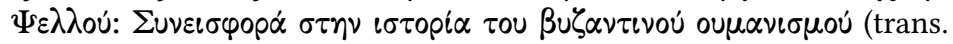

A. Tzelesi; Athens 2004).

Loukaki 2013 = Loukaki, M. "Kataphlôros ou Kataphlôron: Notes sur un patronyme byzantin”, Zbornik radova Vizantološkog instituta 50 (2013) 357-365.

Luard 1858 = Luard, H. R. A Catalogue of the Manuscripts preserved in the Library of the University of Cambridge, vol. 3 (Cambridge 1858).

Magdalino 1987 = Magdalino, P. "The Literary Perception of Everyday Life in Byzantium: Some General Considerations and the Case of John Apokaukos", Byzantinoslavica 47 (1987) 28-38.

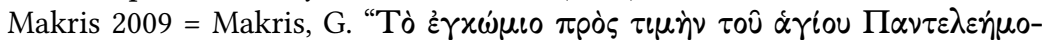

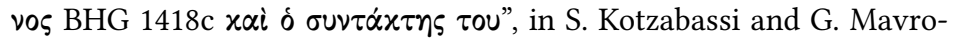
matis (eds.) Realia Byzantina (Berlin 2009) 103-135.

Mango-Efthymiadis 1997 = Mango, C. and S. Efthymiadis (eds.) The Correspondence of Ignatios, the Deacon: Text, Translation, and Commentary (Washington, D.C. 1997).

Mango-Ševčenko 1973 = Mango, C. and I. Ševčenko, "Some Churches and Monasteries on the Southern Shore of the Sea of Marmara", Dumbarton Oaks Papers 27 (1973) 235-277.

Martini and Bassi 1906 = Martini, A. and D. Bassi, Catalogus codicum graecorum Bibliothecae Ambrosianae (Milan 1906).

Mazzucchi 1990 = Mazzucchi, C. M. "Longino in Giovanni di Sicilia", Aevum 6 (1990) 183-198.

Mazzucchi 2003 = Mazzucchi, C. M. "Ambrosianus C 222 inf. (Graecus 886): il codice e il suo autore. Parte prima: il codice”, Aevum 77 (2003) 263-275.

Mazzucchi 2004 = Mazzucchi, C. M. “Ambrosianus C 222 inf. (Graecus 886): il codice e il suo autore. Parte seconda: l'autore”, Aevum 78 (2004) 411-440. 
Mercati 1948 = Mercati, S. G. "Ufficio di Giovanni Mauropode Euchaita cornposto dal nipote Teodoro", in Mémorial Louis Petit: mélanges d'histoire et d'archéologie byzantines (Bucharest 1948) 347-360.

Mercati and Cavalieri 1923 = Mercati, G. and P. Franchi de' Cavalieri, Codices Vaticani Graeci, I. Codices 1-329 (Rome 1923).

Mioni 1972 = Mioni, E. Bibliothecae Divi Marci Venetiarum codices graeci manuscripti, vol. III (Rome 1972).

Mioni 1985 = Mioni, E. Bibliothecae Divi Marci Venetiarum codices graeci manuscripti, vol. II Thesaurus Antiquus (Rome 1985).

Mioni 1992 = Mioni, E. Catalogus codicum graecorum Bibliothecae Nationalis Neapolitanae, t. 1.1 (Rome 1992).

Mogenet 1989 = Mogenet, I. Codices Barberiniani graeci, Tomus II: Codices 164-281. Enarrationes complevit I. Leroy, addenda et indices curavit P. Canart (Vatican 1989).

Molin Pradel 2013 = Molin Pradel, M. Katalog der griechischen Handschriften der Bayerischen Staatsbibliothek München. 2, Codices graeci Monacenses 56-109 (Wiesbaden 2013).

Mondrain 1992 = Mondrain, B. "Copistes et collectionneurs de manuscrits grecs au milieu du XVIe siècle: le cas de Johann Jakob Fugger d'Augsbourg", Byzantinische Zeitschrift 84-85 (1992) 354-390.

Moore 2005 = Moore, P. Iter Psellianum: A Detailed Listing of Manuscript Sources for All Works Attributed to Michael Psellos (Toronto 2005).

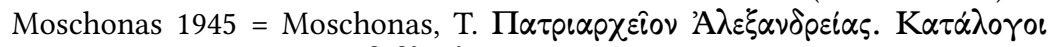

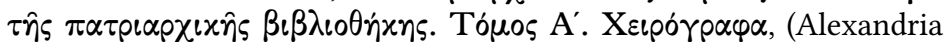
1945).

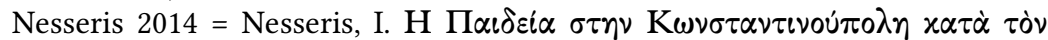
$120 \alpha \iota \dot{v} \nu \alpha$ (PhD diss.; Ioannina 2014), vols. 1 and 2.

Noret 2014 = Noret, J. "L'accentuation byzantine: en quoi et pourquoi elle diffère de l'accentuation "savante» actuelle, parfois absurde", in M. Hinterberger (ed.) The Language of Byzantine Learned Literature (Turnhout 2014) 96-146.

ODB = Kazhdan, A. P. (ed.) The Oxford Dictionary of Byzantium (New York 1991).

Oikonomidès 1960 = Oikonomidès, N. "Un décret synodal inédit du patriarche Jean Xiphilin concernant l'élection et l'ordination des évêques”, Revue des études byzantines 18 (1960) 55-78.

Oikonomides 1983 = Oikonomides, N. Review of Karpozilos, A. $\Sigma u \mu \beta 0 \lambda \dot{\eta} \sigma \tau \dot{\eta}$

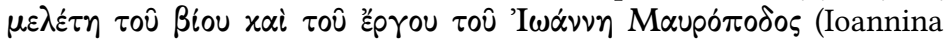
1982) in Südostforschungen 42 (1983) 486-488.

Oikonomidès 1984 = Oikonomidès, N. Actes de Docheiariou (Paris 1984) 211-213.

Oikonomidès 1996 = Oikonomidès, N. Fiscalité et exemption fiscale à Byzance (IX-XI s.) (Athens 1996).

Omont 1888 = Omont, $\mathrm{H}$. Inventaire sommaire des manuscrits grecs de la Bibliothèque Nationale, III (Paris 1888). 
Op de Coul 2007 = Op de Coul, M.D.J. Théodore Prodrome. Lettres et Discours. Édition, Traduction, Commentaire, vols. I-II (PhD thesis; Paris 2007).

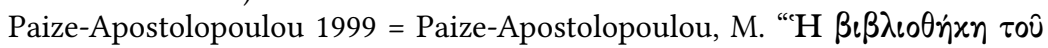

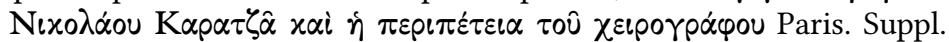
gr. 1375”, 'E $\lambda \lambda \eta \nu \iota x \dot{\alpha} 49$ (1999) 61-72.

Palabiyik 2015 = Palabiyik, N. "An Early Case of the Printer's SelfCensorship in Constantinople”, The Library 16 (2015) 381-404.

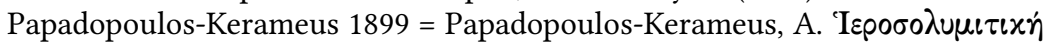

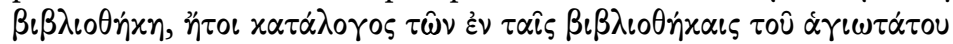

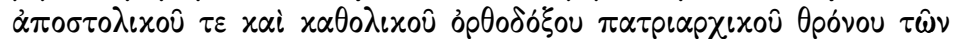

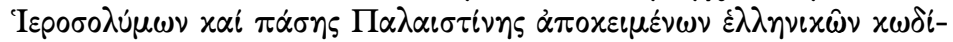
$\chi \omega \nu$, vol. 4 (St. Petersburg 1899).

Papagiannis 1997 = Papagiannis, G. (ed.) Theodoros Prodromos: jambische und hexametrische tetrasticha auf die haupterzählungen des alten und des Neuen Testaments (Wiesbaden 1997).

Papaioannou 1998Papaioannou, S. "Das Briefcorpus des Michael Psellos: Vorarbeiten $\mathrm{zu}$ einer kritischen Neuedition. Mit einem Anhang: Edition eines unbekannten Briefes,” Jahrbuch der österreichischen Byzantinistik 48 (1998) 67-117.

Papaioannou 2012 = Papaioannou, S. "Fragile Literature: Byzantine LetterCollections and the Case of Michael Psellos", in P. Odorico (ed.) La face cachée de la littérature byzantine. Le texte en tant que message immédiat (Paris 2012) 289-328.

Papaioannou 2013 = Papaioannou, S. Michael Psellos: Rhetoric and Authorship in Byzantium (Cambridge and New York 2013).

Papaioannou 2014 = Papaioannou, S. "Byzantine Historia", in K. Raaflaub (ed.) Thinking, Recording, and Writing History in the Ancient World (Malden, MA and Oxford 2014) 297-313.

Papaioannou 2017 = Papaioannou, S. Christian Novels from the Menologion of Symeon Metaphrastes (Cambridge MA 2017).

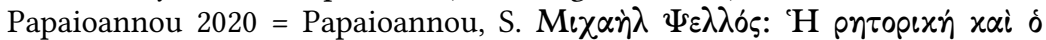

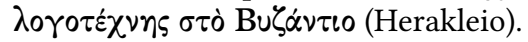

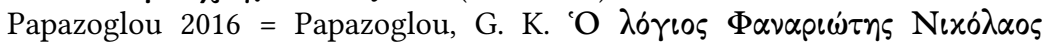

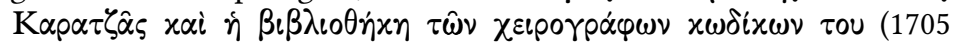

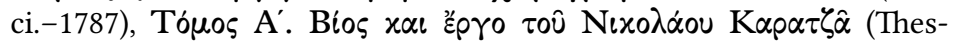
salonike 2016).

Parpulov 2014 = Parpulov, G. R. Toward A History of Byzantine Psalters: 850-1350 (Plovdiv 2014).

Patillon-Brisson 2001 = Patillon, M. and L. Brisson, Longin: Fragments; Art Rhétorique; Rufus: Art Rhétorique (Paris 2001).

Pérez Martín 2001 = Pérez Martín, I. "Antonio Agustín y Manuel Provataris en Venecia (a. 1543)”, Miscellanea Bibliothecae Apostolicae Vaticanae 8 (2001) 299-311. 
Pérez Martín 2010 = "L'écriture de l'hypatos Jean Pothos Pédiasimos d'après ses scholies aux Elementa d'Euclide", Scriptorium 64.1 (2010) 109-119.

Pérez Martín 2013 = Pérez Martín, I. "The Transmission of Some Writings by Psellos in Thirteenth-Century Constantinople', in A. Rigo (ed.) Theologica minora: The Minor Genres of Byzantine Theological Literature, Moscow, 21-22 November 2011, St Tikhon's Orthodox University, Faculty of Theology (Turnhout 2013) 159-174 and 180-185.

Pérez Martín 2014 = Pérez Martín, I. "The Transmission of Michael Psellos' Writings on Meteorologica”, in J. Signes Codoñer and I. Pérez Martín (eds.) Textual Transmission in Byzantium: Between Textual Criticism and Quellenforschung (Turnhout 2014) 291-311.

Perez Martín 2018 = Pérez Martín, I. "Miguel Pselo, Sobre el mapa: Un estrabón oculto”, in E. Castro-Páez (ed.) De nuevo sobre Estrabón. Geografía, cartografía, historiografía y tradición (Seville 2018) 111-136.

Pérez Martín forthcoming = Pérez Martín, I. "Once more on the Life and Handwriting of the Hypatos ton Philosophon John Pothos Pediasimos".

Pietrobelli 2009 = Pietrobelli, A. "L'itinéraire de deux manuscrits de Galien à la Renaissance”, Revue d'histoire des textes 4 (2009) 79-114.

Pingree 1977 = Pingree, D. "The Library of George, Count of Corinth", in Studia Codicologica (Berlin 1977) 351-362.

PLP = Trapp E. et. al. Prosopographisches Lexikon der Palaiologenzeit (Vienna 1976-1996).

PLRE I = Martindale, J. R. The Prosopography of the Later Roman Empire, v. 1. A.D. 260-395 (Cambridge 1971)

PmbZ = Lilie, R.-J. et al., Prosopographie der mittelbyzantinischen Zeit. Abt. 1 (641-867) and Abt. 2 (867-1025) (Berlin 1998-2013).

Polemis 1968 = Polemis, D. I. The Doukai: A Contribution to Byzantine Prosopography (London 1968).

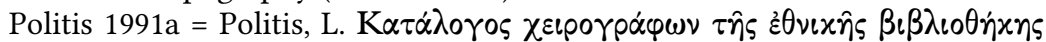

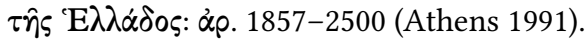

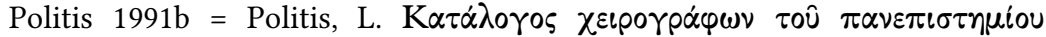

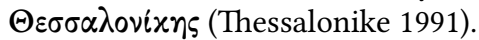

Puntoni 1896 = Puntoni, V. "Indice dei codici greci della Biblioteca Estense di Modena”, Studi Italiani di Filologia Classica 4 (1896) 379-536

Regtuit 1992 = Regtuit, R. F. Severian of Gabala: Homily on the Incarnation of Christ (CPG 4204) (Amsterdam 1992).

Reinsch 2008 = Reinsch, D. R. "Stixis und Hören", in B. Atsalos and N. Tsironi (eds.) Actes du VIe Colloque International de Paléographie Grecque (Drama, 21-27 septembre 2003), vol. I (Athens 2008) 259-269.

Reinsch 2012 = Reinsch, D. R. "What Should an Editor Do with a Text like the Chronographia of Michael Psellos", in A. Bucossi and E. Kihlman (eds.) Ars Edendi. Lecture Series, Vol. II. (Stockholm 2012) 131-154.

Reinsch 2014 = Reinsch, D. R. (ed.) Michaelis Pselli Chronographia, 2 vols. (Berlin and Boston 2014). 
Reinsch 2017 = Reinsch, D. R. "Venomous Praise: Some Remarks on Michael Psellos' Letters to Leon Paraspondylos”, in M. Jeffreys and M. D. Lauxtermann (eds.) The Letters of Psellos: Cultural Networks and Historical Realities (Oxford and New York 2017) 128-140.

Reinsch and Kambylis $2001=$ Reinsch, D. R. and A. Kambylis, Annae Comnenae Alexias (Berlin and New York 2001).

Renauld 1920 = Renauld, É. Étude de la langue et du style de Michel Psellos (Paris 1920).

RGK = Gamillscheg, E., D. Harlfinger, and H. Hunger, Repertorium der griechischen Kopisten 800-1600, 3 vols. (Vienna 1981-1997).

Riedinger 2010 = Riedinger, J.-C. "Quatre étapes de la vie de Michel Psellos", Revue des études byzantines 68 (2010) 5-60.

Riehle forthcoming = Riehle, A. Companion to Byzantine Epistolography (Leiden and Boston, forthcoming).

Rostagno and Festa 1961 = Rostagno, E. and N. Festa, "Indice dei codici greci laurenziani non compresi nel catalogo del Bandini”, in A. M. Bandini, Catalogus codicum manuscriptorum Bibliothecae Mediceae Laurentianae. Accedunt supplementa tria ... Accuravit F. Kudlien (Leipzig 1961), $3^{*}-62^{*}=$ Studi Italiani di Filologia Classica 1 (1893) 192-232.

Seibt I = Seibt, W. Die byzantinischen Bleisiegel in Österreich. I. Kaiserhof (Vienna 1978).

Seibt II = Seibt, W. Die byzantinischen Bleisiegel in Österreich. II. Kaiserhof (Vienna 2004).

Seibt 19761 = Seibt, W. Die Skleroi: eine prosopographisch-sigillographische Studie (Vienna 1976).

Seibt 19762 = Seibt, W. "Ioannes Skylitzes. Zur Person des Chronisten", Jahrbuch der österreichischen Byzantinistik 25 (1976) 81-85.

Sideras 1994 = Sideras, A. Die byzantinischen Grabreden: Prosopographie, Datierung, Überlieferung 142 Epitaphien und Monodien aus dem byzantinischen Jahrtausend (Vienna 1994).

Silvano 2018 = Silvano, L. "Il monaco Elia tra cielo e inferno: nota a Psello, epist. 98 Kurtz-Drexl”, Res Publica Litterarum 40 (2017) [2018].

Snipes 1981 = Snipes, K. "A Letter of Michael Psellos to Constantine the Nephew of Michael Cerularios”, Greek, Roman and Byzantine Studies 22 (1981) 89-107.

Spadaro 1976 = Spadaro, M. D. "Sull'epistola di Psello 44 Sathas", Siculorum Gymnasium ns 29 (1976) 427-435.

Spingou forthcoming = Spingou, F. Poetry for the Comnenoi. The Anthologia Marciana: Sylloge B and C (Oxford forthcoming).

Spyridon of Lavra and Eustratiades 1925 = Spyridon of Lavra and S. Eustratiades, Catalogue of the Greek Manuscripts in the Library of the Lavra on Mount Athos (Cambridge 1925).

Stavrakos $2000=$ Stavrakos, C. Die byzantinischen Bleisiegel mit Familiennamen aus der Sammlung des Numismatischen Museums Athen (Wiesbaden 2000). 
STC = Pollard, A. W. A Short-title Catalogue of Books printed in England, Scotland, \& Ireland and of English Books Printed Abroad, 1475-1640; 2nd ed. revised and enlarged by W. A. Jackson and F. S. Ferguson, completed by K. F. Pantzer (London 1976-1991).

Stefec 2011a = Stefec, R. "Anmerkungen zu weiteren Epigrammen in epigraphischer Auszeichnungsmajuskel”, Byzantion 81 (2011) 326-361.

Stefec 2011b = Stefec, R. "Das Briefdossier des Georgios Kalybas im Codex Vind. theol. gr. 227”, Römische historische Mitteilungen 53 (2011) 121-150.

Stefec 2012 = Stefec, R. "Zur Geschichte der Handschriften des Francesco

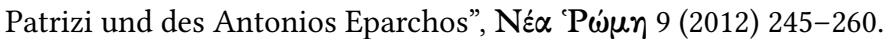

Stefec 2014 = Stefec, R. "Die Handschriften der Sophistenviten Philostrats", Römische historische Mitteilungen 56 (2014) 137-206.

Stevenson 1885 = Stevenson, H. Codices Manuscripti Palatini Graeci Bibliothecae Vaticanae (Rome 1885).

Studemund and Cohn 1890 = Studemund W. and L. Cohn, Verzeichniss der griechischen Handschriften der Königlichen Bibliothek zu Berlin, vol. I (Berlin 1890).

Todt 2001 = Todt, Kl.-P. "Region und griechisch-orthodoxes Patriarchat von Antiocheia in mittelbyzantinischer Zeit und im Zeitalter der Kreuzzüge (969-1204)", Byzantinische Zeitschrift 94 (2001) 239-267.

TIB 2 = Hild, F. and M. Restle, Kappadokien (Vienna 1981).

TIB $10=$ Koder, J. et al. Aigaion Pelagos (Vienna 1998).

TIB 12 = Külzer, A. Ostthrakien (Vienna 2008).

Uthemann 1985 = Uthemann, K. Anastasii Sinaitae Sermones duo in constitutionem hominis secundum imaginem Dei, necnon Opuscula aduersus monotheletas (Turnhout 1985).

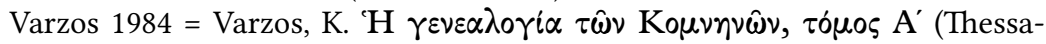
lonike 1984).

Vladimir 1894 = Archimandrite Vladimir, Систематическое описание рукописей Московской Синодальной (Патриаршей) библиотеки, Ч. I: Рукописи греческие (Moscow 1894).

Vogel and Gardthausen 1909 = Vogel, M. and V. Gardthausen, Die griechischen Schreiber des Mittelalters und der Renaissance (Leipzig 1909).

Volk 1955 = Volk, O. Die byzantinischen Klosterbibliotheken von Konstantinopel, Thessalonike und Kleinasien (Munich 1955).

Volk 1990 = Volk, R. Der medizinische Inhalt der Schriften des Michael Psellos (München 1990).

Volk 2002 = Volk, R. "Eine seltsame Metaphrase von Psellos-Briefen", Jahrbuch der österreichischen Byzantinistik 52 (2002) 185-189.

Walz 1833 = Walz, C. Rhetores Graeci, vol. 5. (Stuttgart 1833).

Vasiljevskij 1896 = Vasiljevskij, V. "Epirotica saeculi XIII.”, Vizantiǔskiı̌ vremennik 3 (1896) 241-299.

Wassiliou 2002 = Wassiliou, A.-K. "Die Familie Hexamilites. Ein Beitrag zur

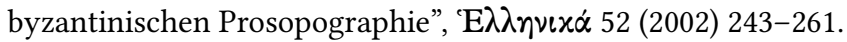


Wassiliou-Seibt I = Wassiliou-Seibt, A.-K. Corpus der byzantinischen Siegel mit metrischen Legenden. Teil 1. Einleitung, Siegellegenden von Alpha bis inklusive My (Vienna 2011).

Wassiliou-Seibt 2011 = Wassiliou-Seibt, A.-K. "Die Neffen des Patriarchen Michael I. Kerullarios (1043-1058) und ihre Siegel. Ikonographie als Ausdrucksmittel der Verwandtschaft”, Bulgaria Mediaevalis 2 (2011) 107-119.

Wassiliou-Seibt 2012 = Wassiliou-Seibt, A.-K. "Die Familie Xiphilinos im 11. Jh. Der Beitrag der Siegel”, in B. Caseau (ed.) Les réseaux familiaux. Antiquité tardive et Moyen Âge (Paris 2012) 307-323.

Wassiliou-Seibt 2018 = Wassiliou-Seibt, A.-K. "Nochmals zum cursus honorum des Konstantinos, des Neffen des Patriarchen Michael I. (Kerullarios)," Zbornik radova Vizantološkog instituta 55 (2018) 65-80.

Weichert 1910 = Weichert, V. (ed.) Demetrii et Libanii qui feruntur Tú $\pi$ o

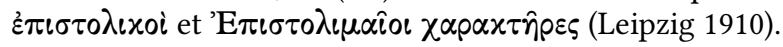

Weiss 1972 = Weiss, G. "Forschungen zu den noch nicht edierten Schriften des Michael Psellos", Byzantina 4 (1972) 9-51.

Weiss 1973 = Weiss, G. Oströmische Beamte im Spiegel der Schriften des Michael Psellos (Munich 1973).

Westerink 1951 = Westerink, L. G. "Some Unpublished Letters of Blemmydes”, Byzantinoslavica 12 (1951) 43-55.

Westerink 1973 = Westerink, L. G. (ed.) Nicétas Magistros, Lettres d'un exilé (Paris 1973).

Westerink 1987 = Westerink, L. G. "Le Parisinus Gr. 1182 et le Vaticanus Gr. 671 de Psellos", in J. Dummer (ed.) Texte und Textkritik. Eine Aufsatzsammlung (Berlin 1987) 605-609.

Wilson 1973 = Wilson, N. G. Mediaeval Greek Bookhands: Examples Selected from Greek Manuscripts in Oxford Libraries (Cambridge, Mass. 1973).

Wilson 1978 = Wilson N. G. "A Byzantine Miscellany: MS. Barocci 131 described”, Jahrbuch der österreichischen Byzantinistik 27 (1978) 157-179.

Zagklas 2014 = Zagklas, N. Theodore Prodromos: The Neglected Poems and Epigrams (Edition, Translation, and Commentary) (PhD thesis; University of Vienna 2014). 


B I B L I O T H E C A SCRIPTORVM GRAECORVM ET ROMANORVM

T E V B N E R I A N A

B T 2030

CONSILIATORES TEVBNERIANI

\author{
GIAN BIAGIO CONTE \\ JAMES DIGGLE \\ DONALD J. MASTRONARDE \\ FRANCO MONTANARI \\ HEINZ-GÜNTHER NESSELRATH \\ DIRK OBBINK \\ OLIVER PRIMAVESI \\ MICHAEL D. REEVE \\ RICHARD J. TARRANT
}




\title{
MICHAEL PSELLUS \\ EPISTULAE \\ VOLUMEN II
}

\author{
EDIDIT \\ STRATIS PAPAIOANNOU
}

DE GRUYTER 
ISBN 978-3-11-062201-0

e-ISBN (PDF) 978-3-11-062501-1

ISSN 1864-399X

\section{Library of Congress Control Number: 2019936568}

Bibliographic information published by the Deutsche Nationalbibliothek

The Deutsche Nationalbibliothek lists this publication in the Deutsche Nationalbibliografie; detailed bibliographic data are available on the Internet at http://dnb.dnb.de.

(C) 2019 Walter de Gruyter GmbH, Berlin/Boston

Greek font: Orthos by Ralph Hancock

Printing: Hubert \& Co. GmbH \& Co. KG, Göttingen

www.degruyter.com 


\section{TABLE OF CONTENTS}

Preface and Acknowledgments ……............................................. VII

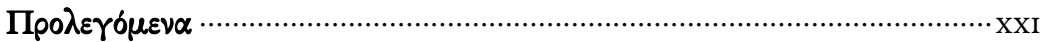

I. Psellos' Letter Collection ….......................................................... XXXII

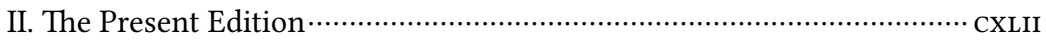

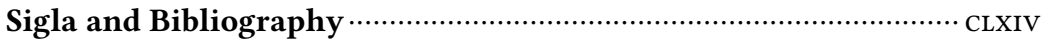

\section{Epistulae}

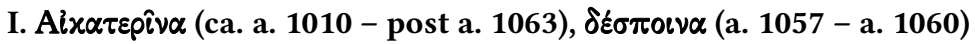

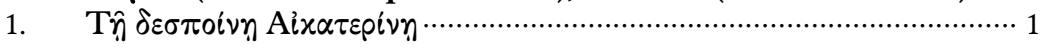

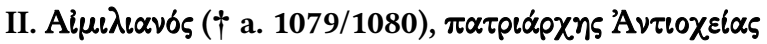

(ca. a. 1060/1065 - a. 1079/1080)

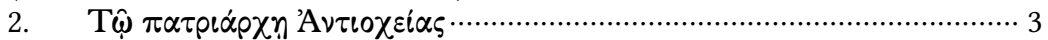

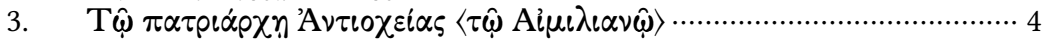

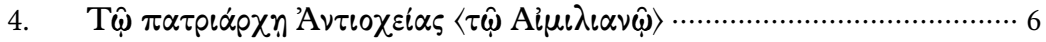

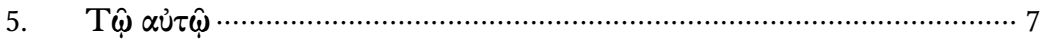

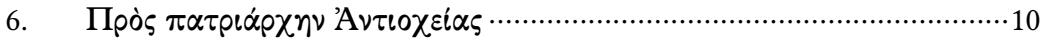

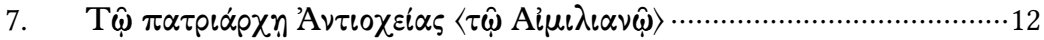

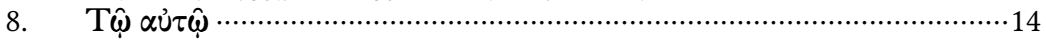

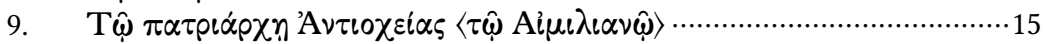

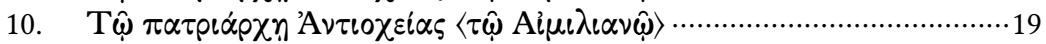

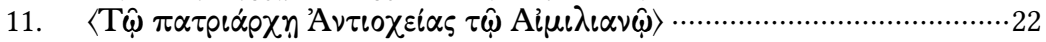

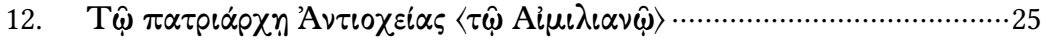

13.

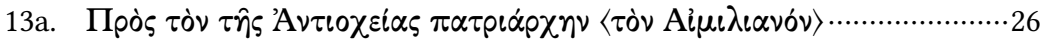

13b. * (versio altera; retractatio in collectione epistolarum Hierothei

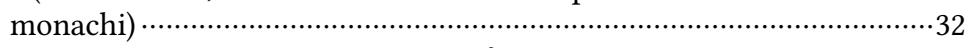

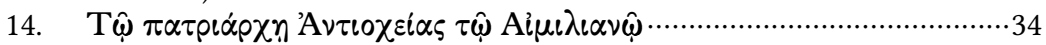

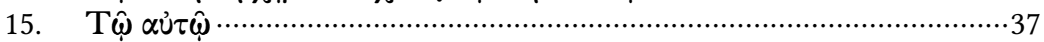

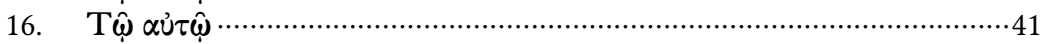

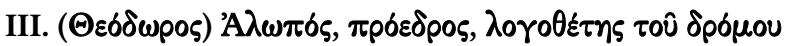

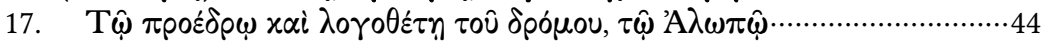

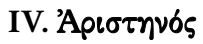

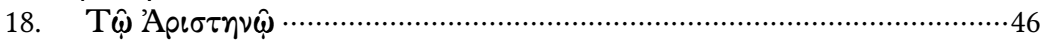

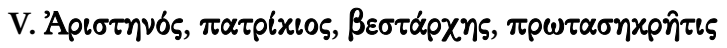

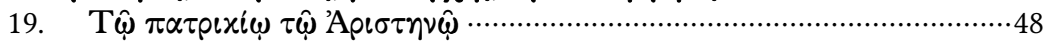




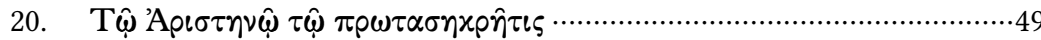

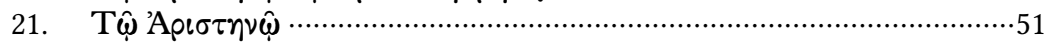

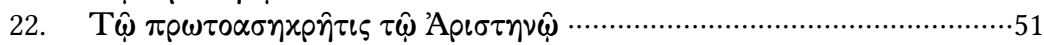

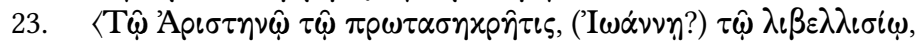

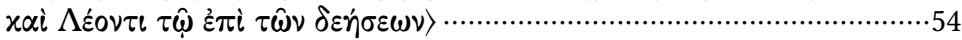

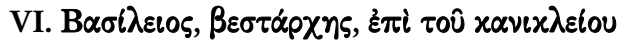

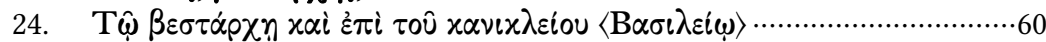

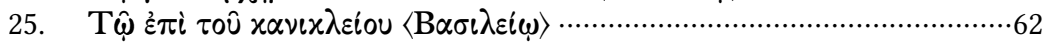

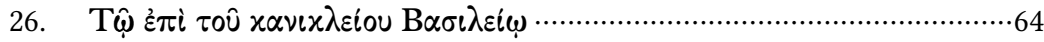

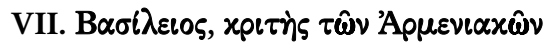

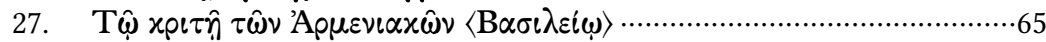

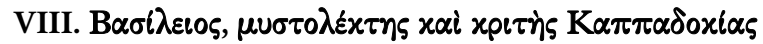

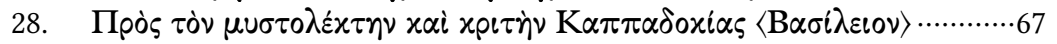

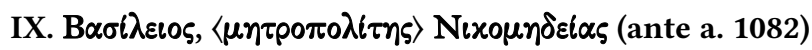

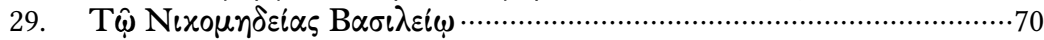

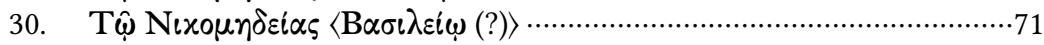

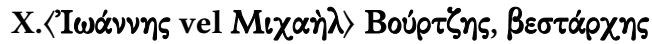

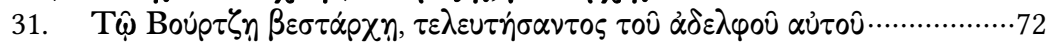

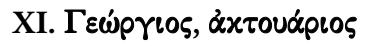

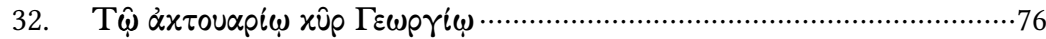

XII. $\Gamma \varepsilon \dot{\rho} p \gamma\llcorner о \varsigma, \sigma u \mu \mu \alpha \theta \eta \tau \dot{n} s$

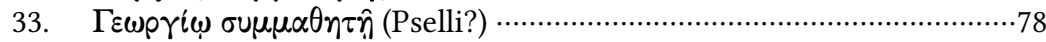

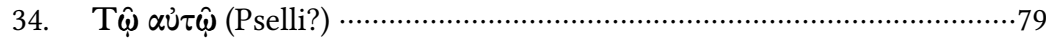

XIII. $\langle\Theta \varepsilon \delta \delta \omega \rho o s ~(?)\rangle \Delta \alpha \lambda \alpha \sigma \sigma \eta \nu \delta ́ \varsigma$

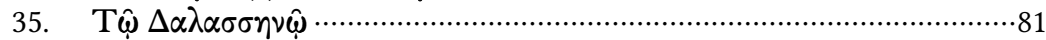

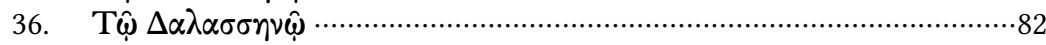

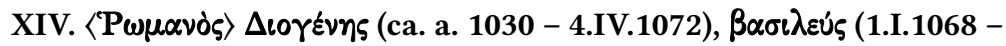
a. 1071)

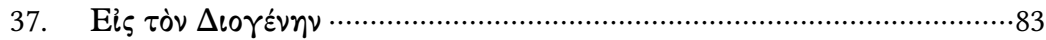

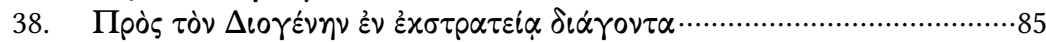

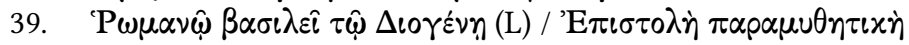

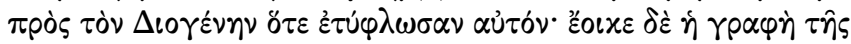

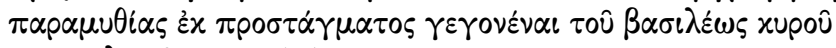

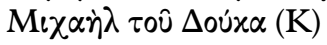




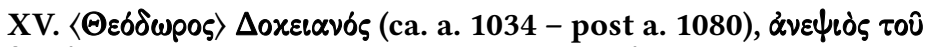

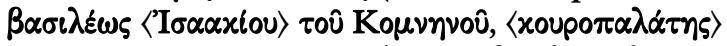

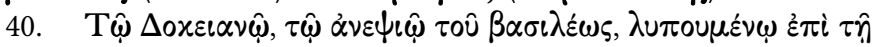

$\tau \varepsilon \lambda \varepsilon \cup \tau \hat{~} \tau 0 \hat{~} \pi \varepsilon \nu \theta \varepsilon \rho \circ \hat{~ \alpha u े \tau o v ̂ ~}$

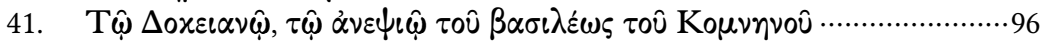

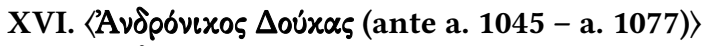

42. $\langle$ A $v \delta \rho o v i x \omega \tau \hat{\varphi} \Delta$ oúx $\alpha(?)\rangle$.

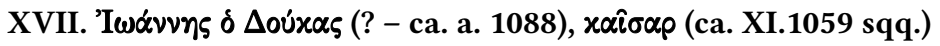

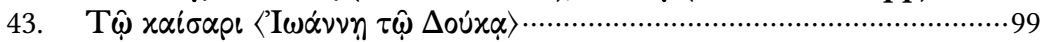

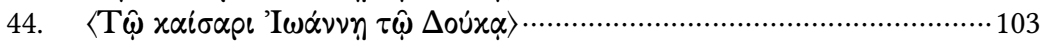

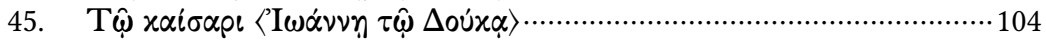

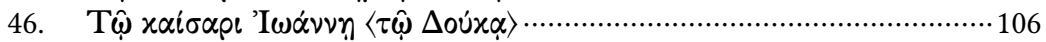

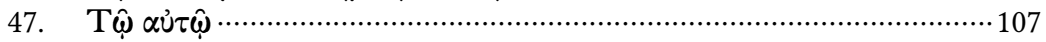

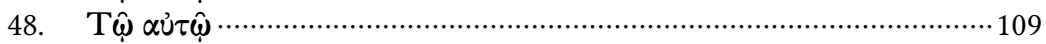

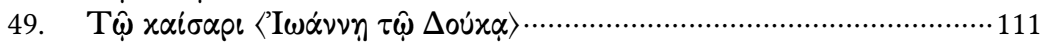

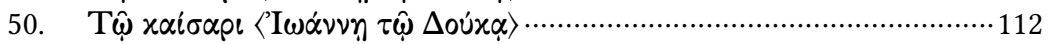

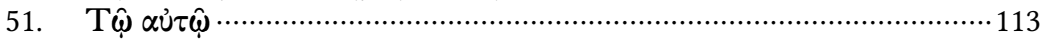

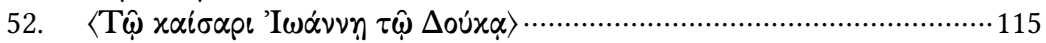

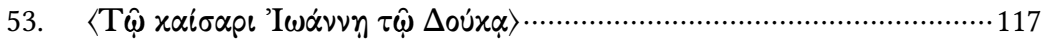

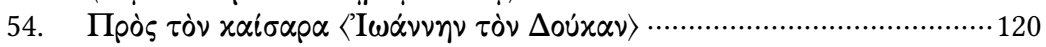

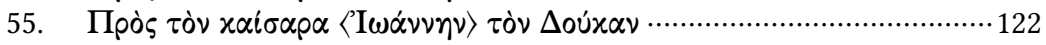

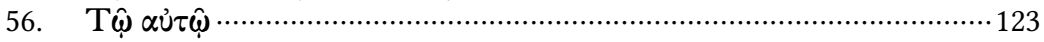

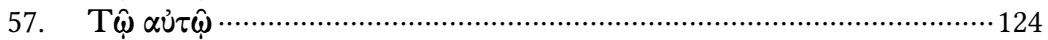

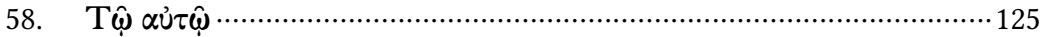

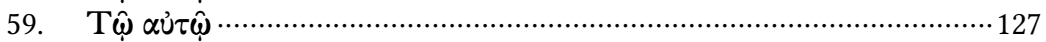

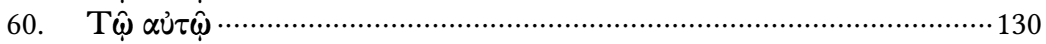

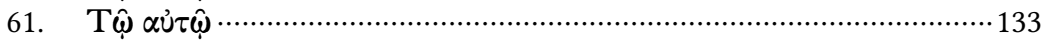

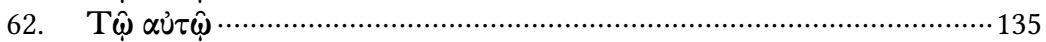

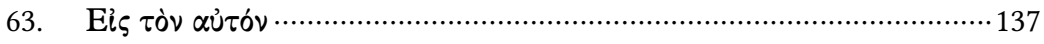

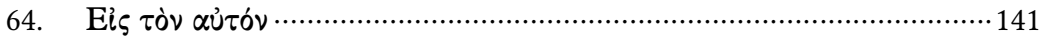

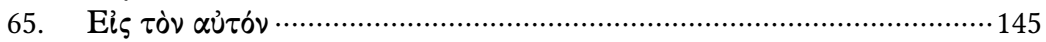

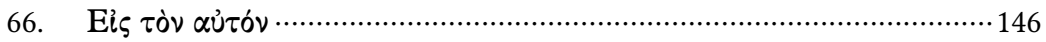

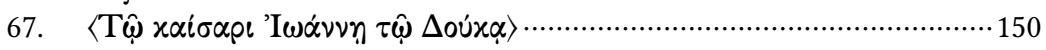

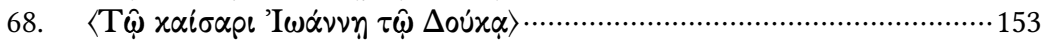

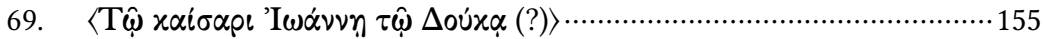

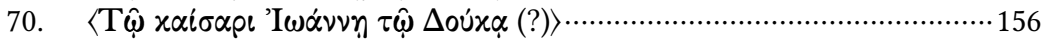

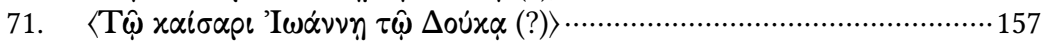

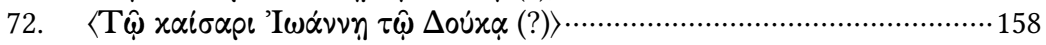

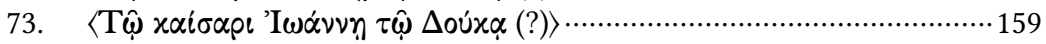

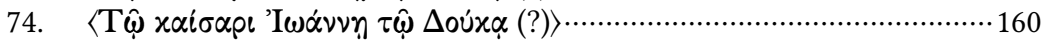

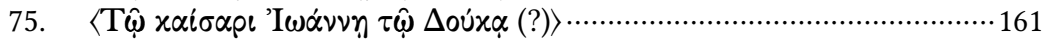

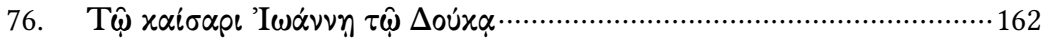

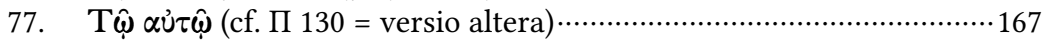




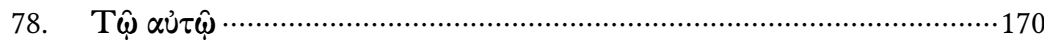

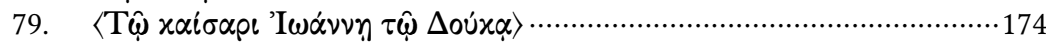

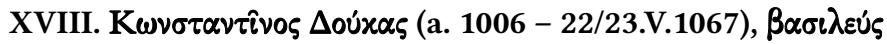

(23/24.XI.1059 - 22/23.V.1067)

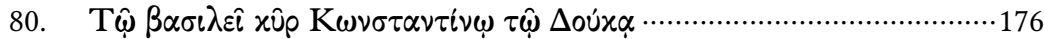

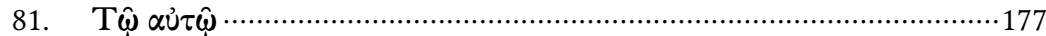

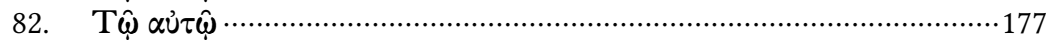

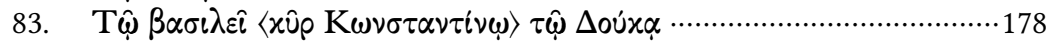

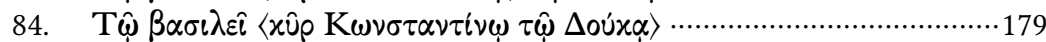

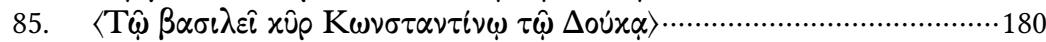

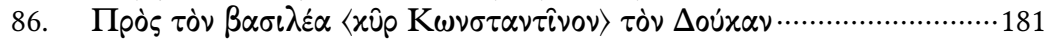

XIX. $\langle M \iota \chi \alpha \eta \dot{\lambda} \Delta \Delta o u ́ x \alpha \varsigma\rangle$ (ca. a. 1050 - ca. a. 1090), $\beta \alpha \sigma \iota \lambda \varepsilon u ́ \varsigma$ (IX.1071 31.III.1078)

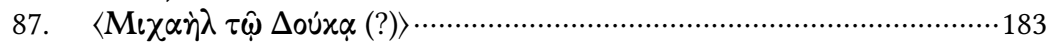

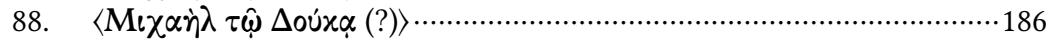

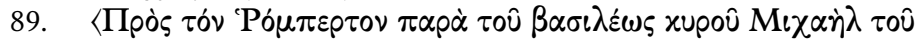
$\Delta o u ́ x \alpha\rangle$.

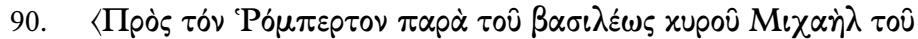
$\Delta$ oúx $\alpha\rangle$.

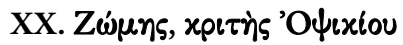

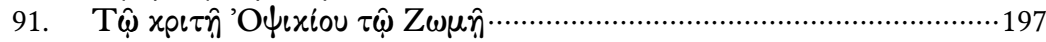

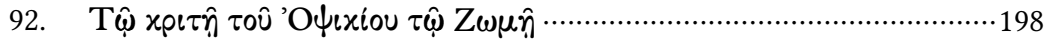

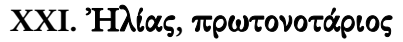

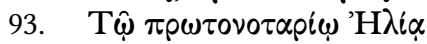

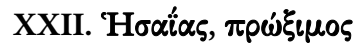

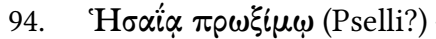

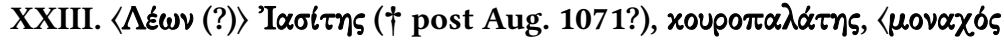

$(?)\rangle$

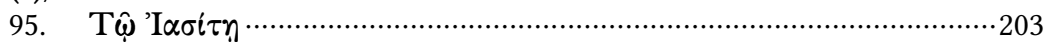

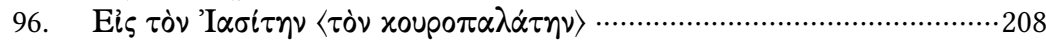

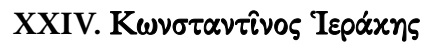

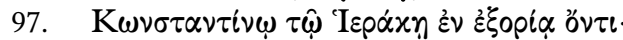

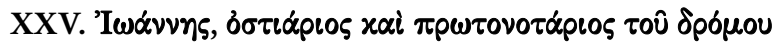

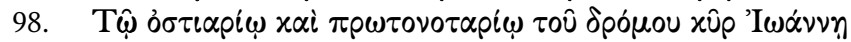

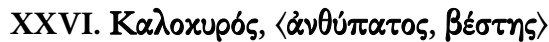

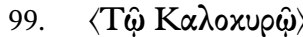




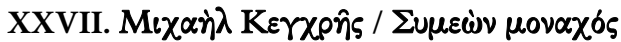

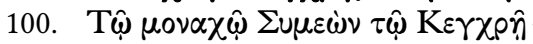

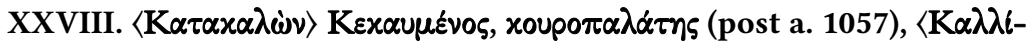

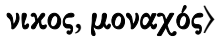

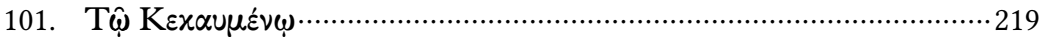

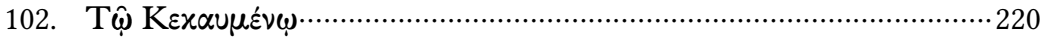

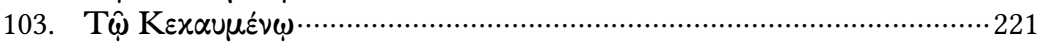

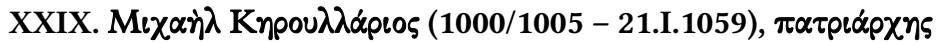

(25.III.1043 - 2.XI.1058)

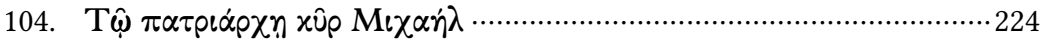

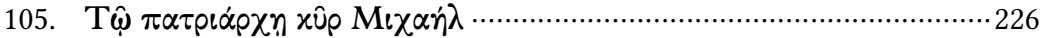

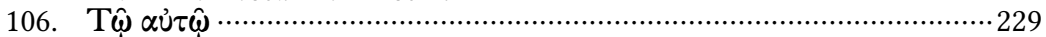

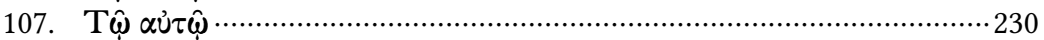

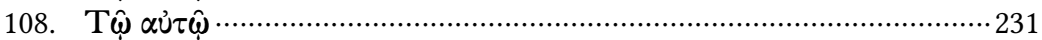

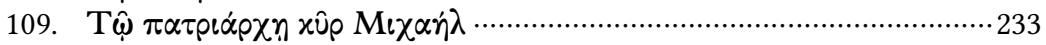

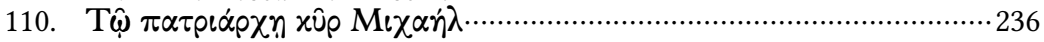

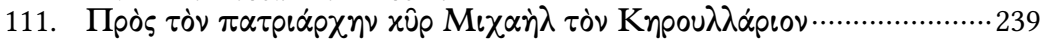

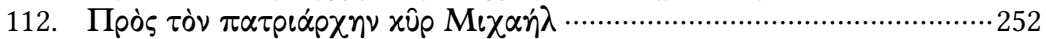

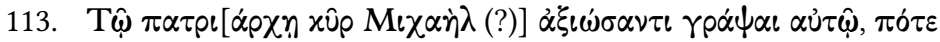

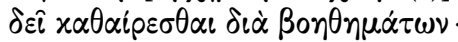

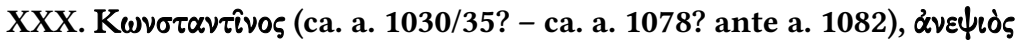

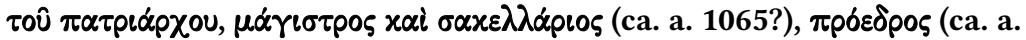

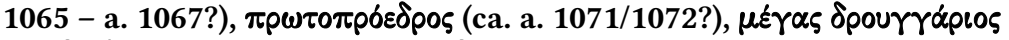

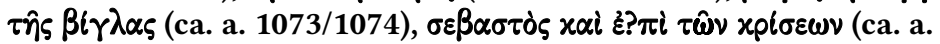
1075/1078?)

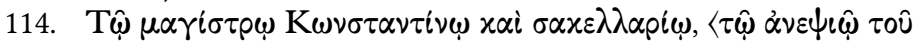
$\pi \alpha \tau \rho \iota \alpha ́ \rho \chi o u ~ M \imath \chi \alpha \hat{\eta} \lambda\rangle$

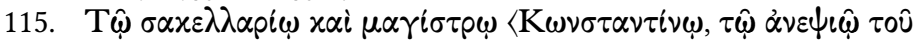

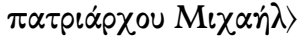

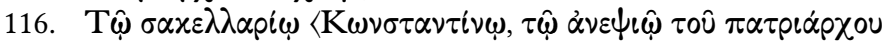
Mi $\chi \propto \dot{\eta} \lambda\rangle$

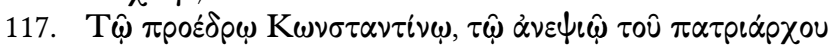
Mıх $\propto \eta^{\prime} \lambda$

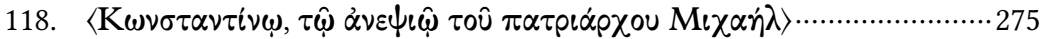

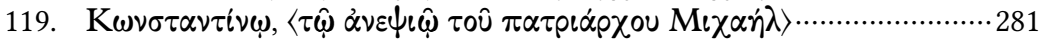

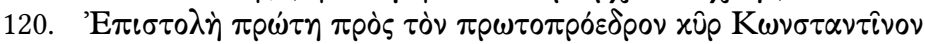

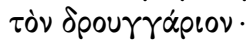

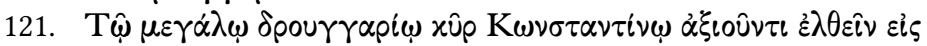

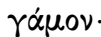

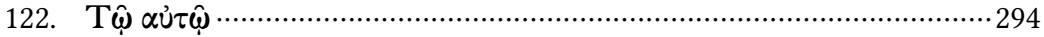

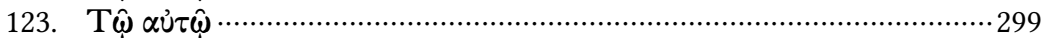

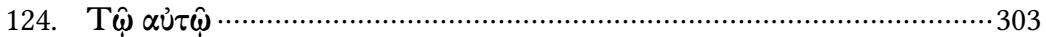




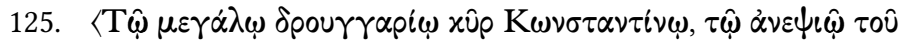

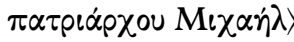

126. T⿳亠丷厂 $\alpha \dot{\tau} \tau \hat{\varphi}$

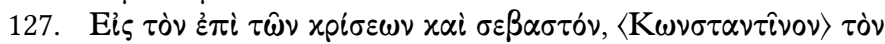

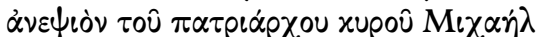

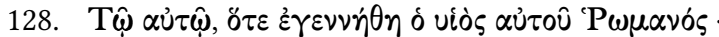

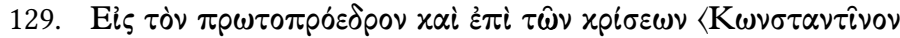

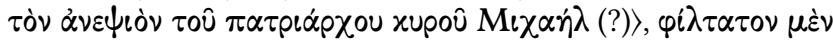

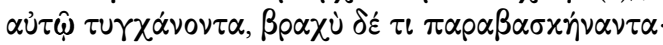

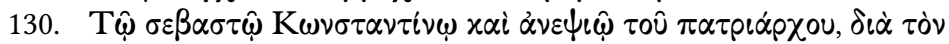

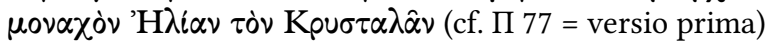

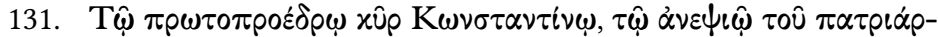

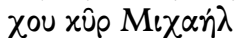

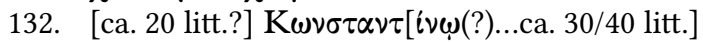

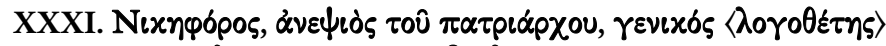

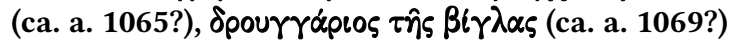

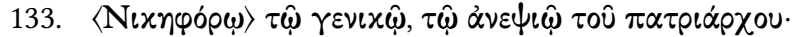

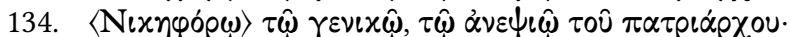

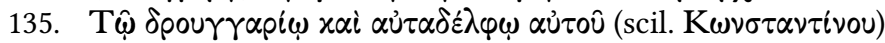

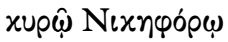

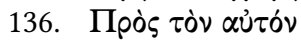

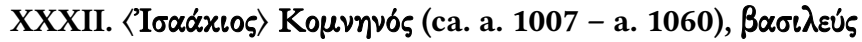

(1.IX.1057 - 22.XI.1059)

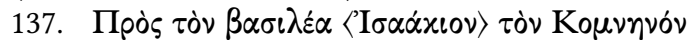

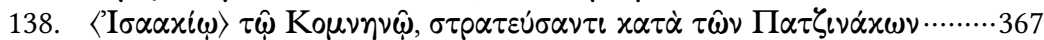

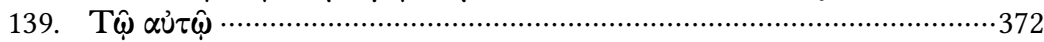

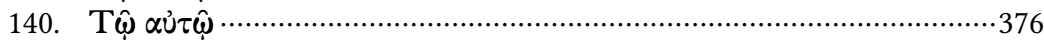

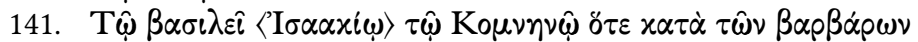
$\dot{\varepsilon} \xi \hat{\eta} \lambda \theta \varepsilon$

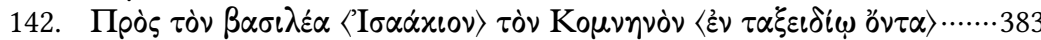

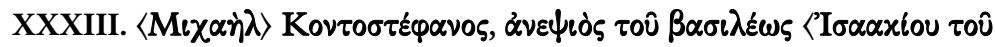

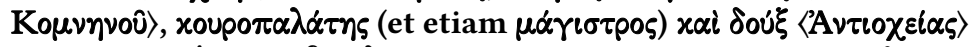

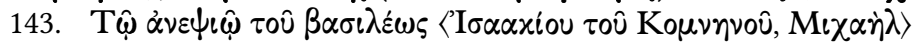

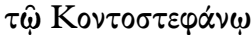

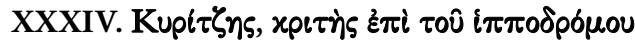

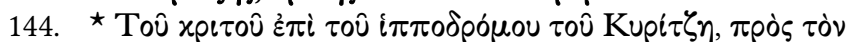
$\Psi \varepsilon \lambda \lambda o^{\prime} \nu$

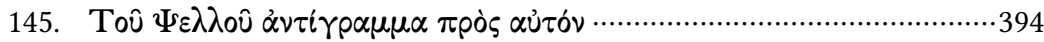

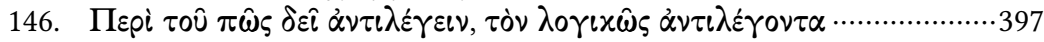




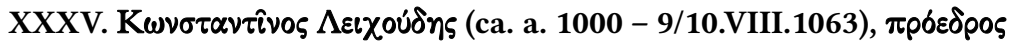

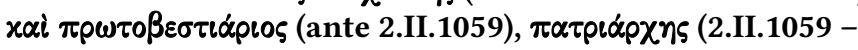
9/10.VIII.1063)

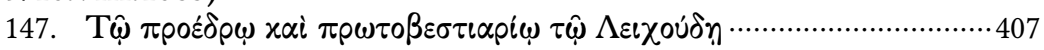

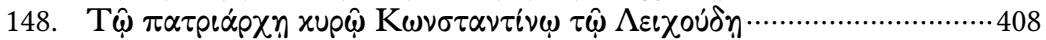

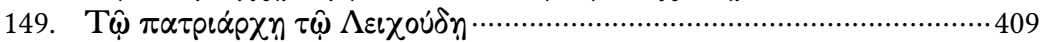

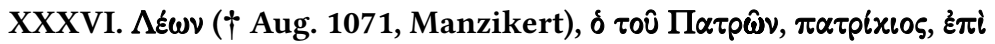
$\tau \hat{\omega} \nu \delta \varepsilon \dot{\eta} \sigma \varepsilon \omega \nu$

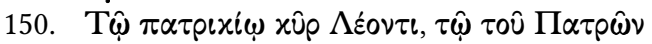

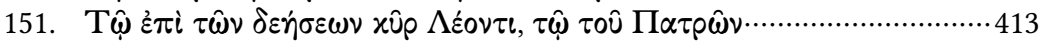

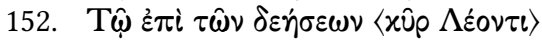

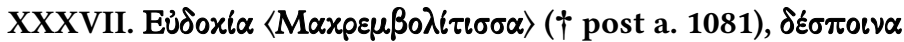
(23/24.XI.1059 - 22/23.V.1067, uxor Const. Ducae; 22/23.V.1067 31.XII.1067; et 1.I.1068 - X.1072, uxor Rom. IV Diog.)

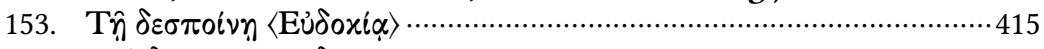

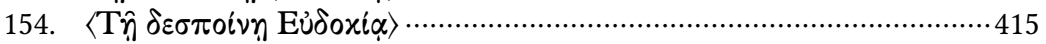

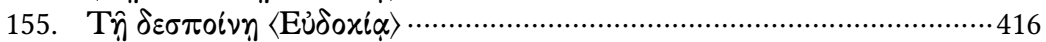

156. $\left\langle\mathrm{T} \hat{\eta} \delta \varepsilon \sigma \pi 0^{\prime} \nu \eta \eta\right.$

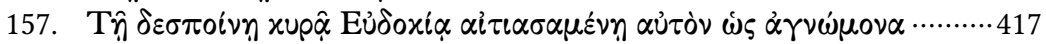

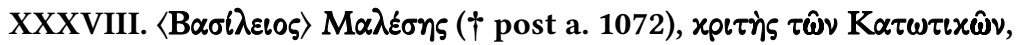

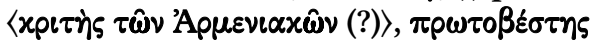

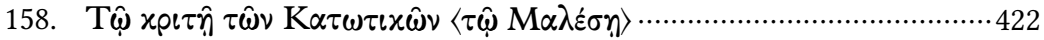

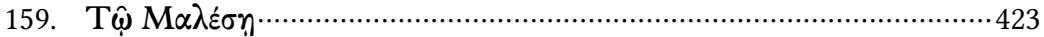

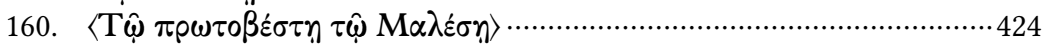

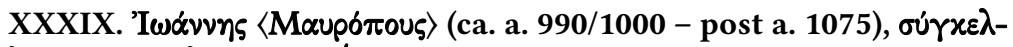

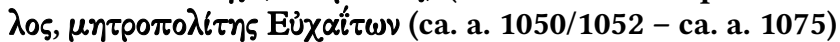

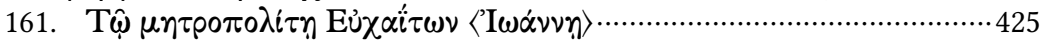

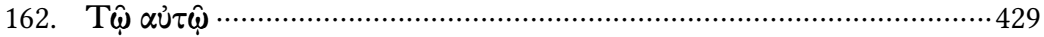

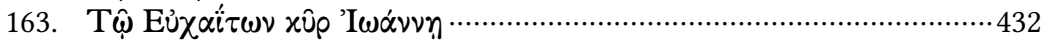

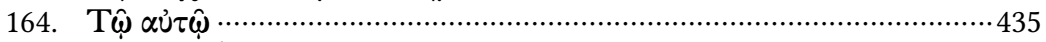

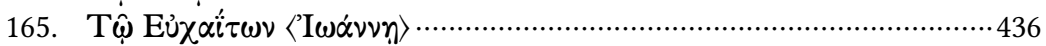

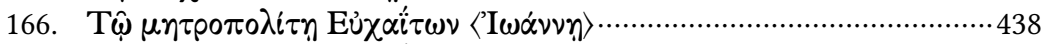

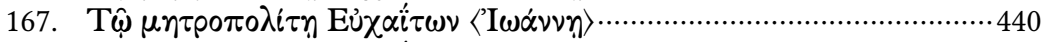

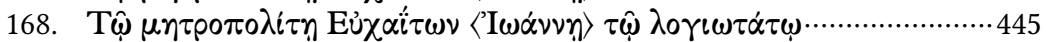

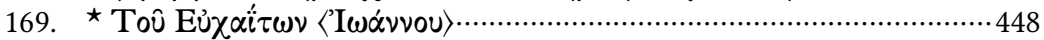

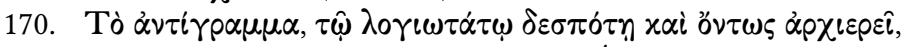

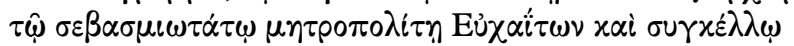

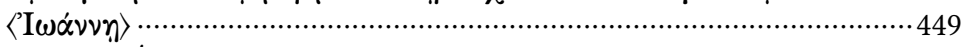

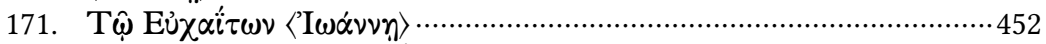

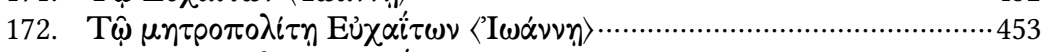

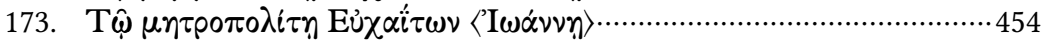




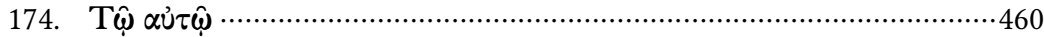

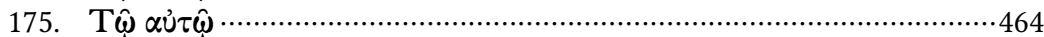

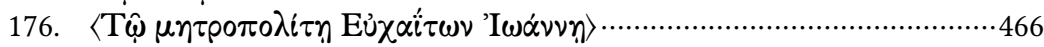

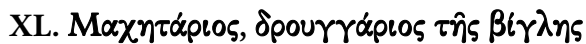

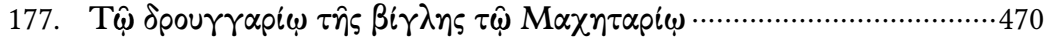

XLI. $\langle\mathbf{M} \iota \chi \alpha \dot{\eta} \lambda(?)\rangle, \beta \varepsilon \delta \sigma \tau \varsigma$

178. $\langle M \iota \chi \alpha \dot{\eta} \lambda(?), \tau \hat{\varphi} \beta \dot{\varepsilon} \sigma \tau \eta\rangle$

XLII. $\langle\mathbf{M} \iota \chi \alpha \dot{\eta} \lambda\rangle, x \rho \imath \tau \dot{\eta} \varsigma \tau \hat{\omega} \nu \mathrm{K}_{\imath} \beta u p \rho \alpha \iota \omega \tau \hat{\omega} \nu$

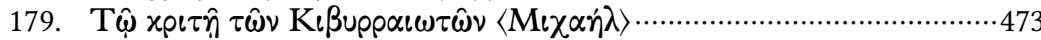

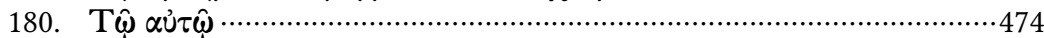

XLIII. Mı $\chi \alpha \dot{\eta} \lambda, \pi \alpha \tau p i x i o s$

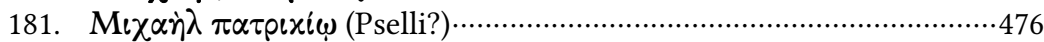

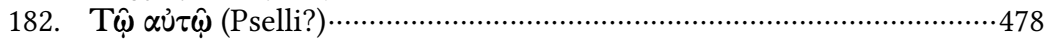

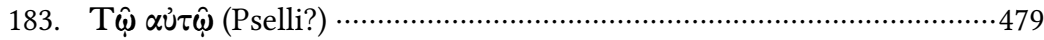

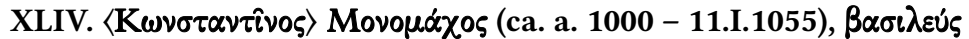
(12.VI.1042 - 11.I.1055)

184. T $\hat{\varphi} \beta \alpha \sigma \iota \lambda \varepsilon \hat{\imath}$ Movo $\mu \alpha \dot{\alpha} \chi$

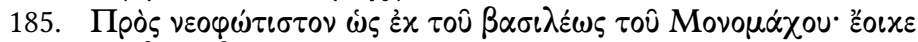

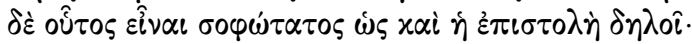

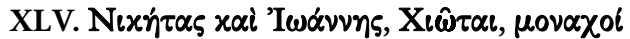

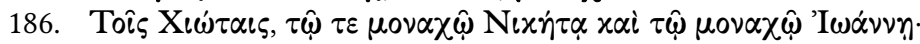

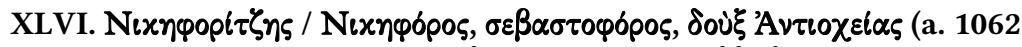

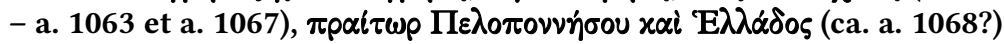

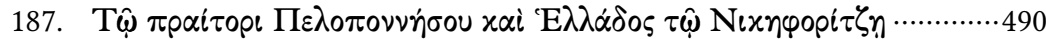

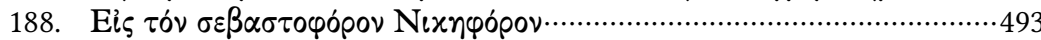

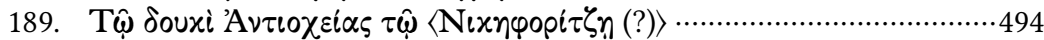

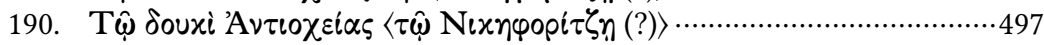

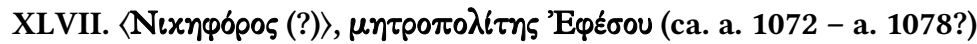

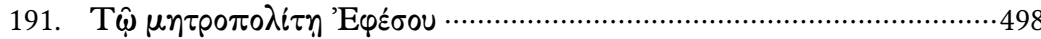

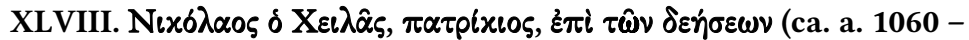
a. 1067?)

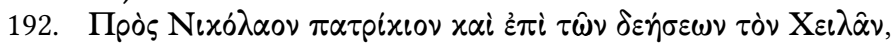

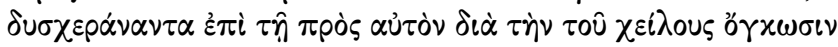
$\dot{\alpha} \sigma \tau \varepsilon \iota \dot{\tau} \tau \tau \iota$ 


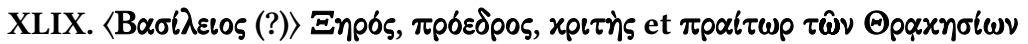

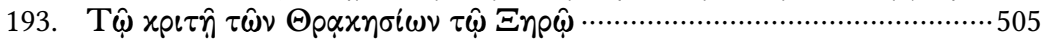

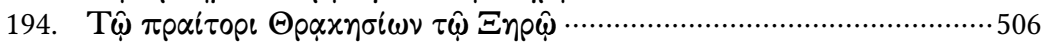

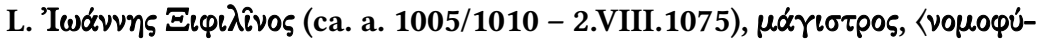

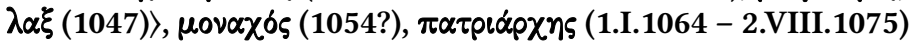

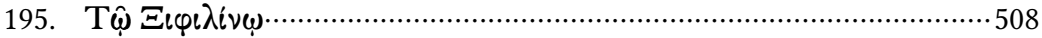

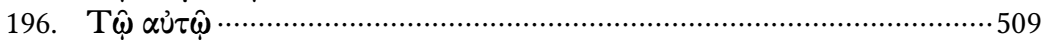

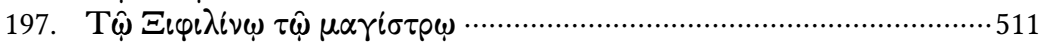

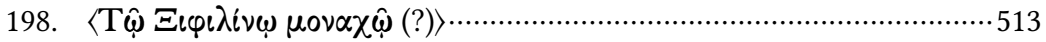

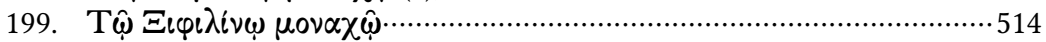

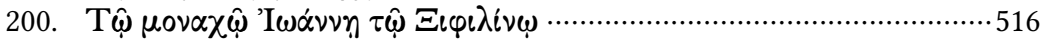

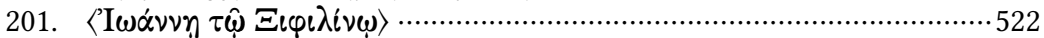

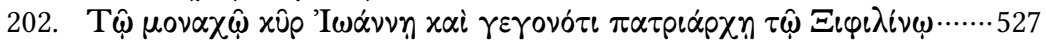

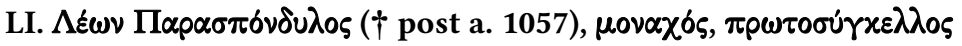
(ca. a. 1055 - a. 1057)

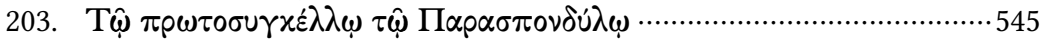

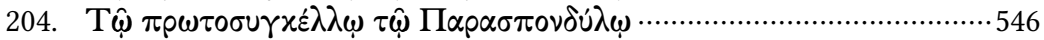

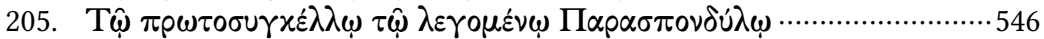

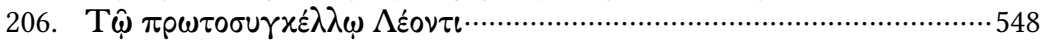

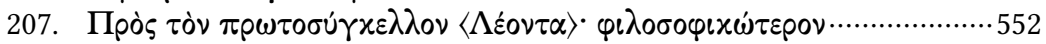

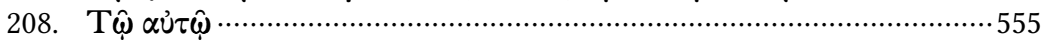

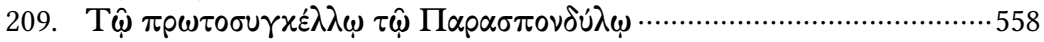

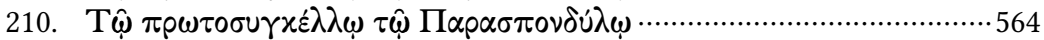

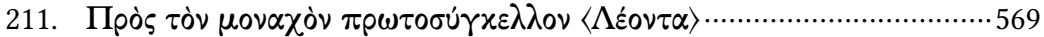

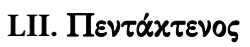

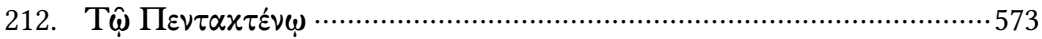

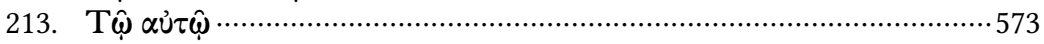

Vol. 2

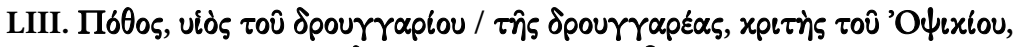

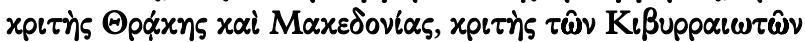

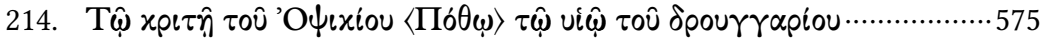

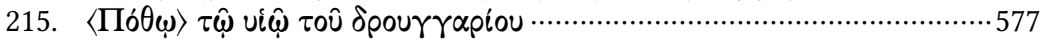

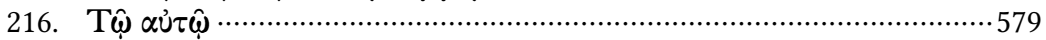

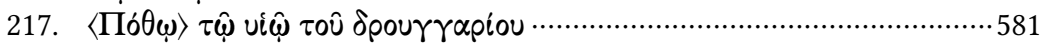

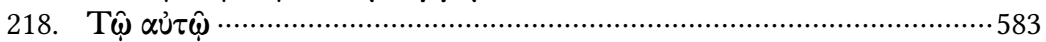

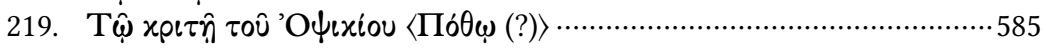

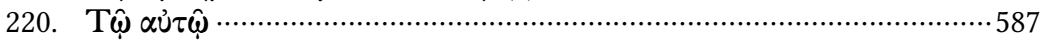

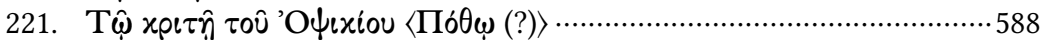

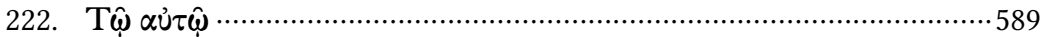




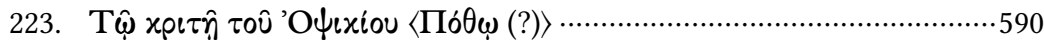

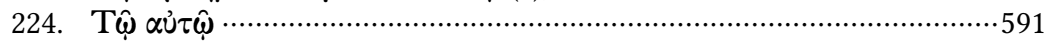

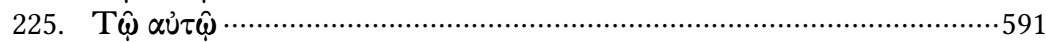

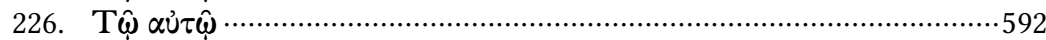

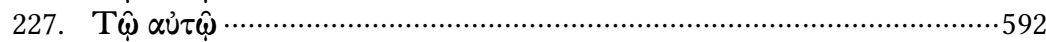

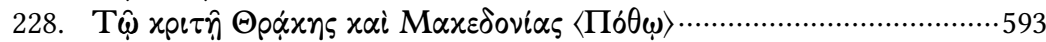

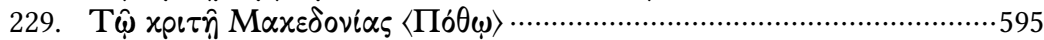

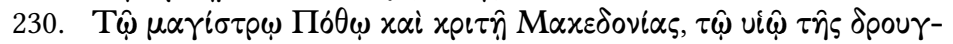

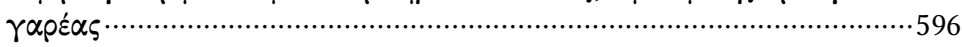

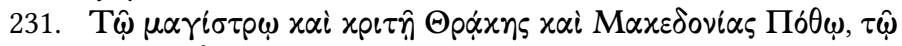

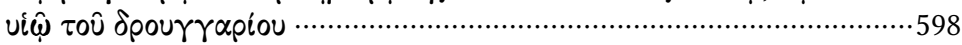

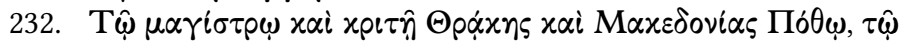

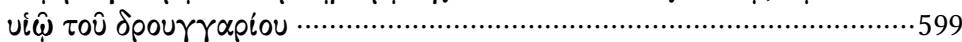

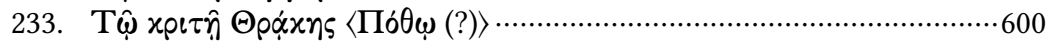

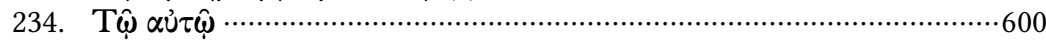

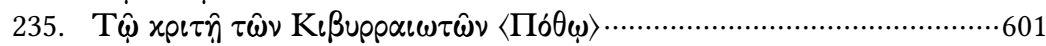

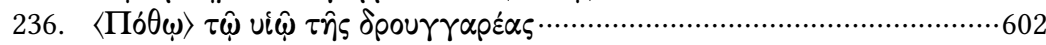

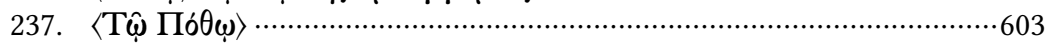

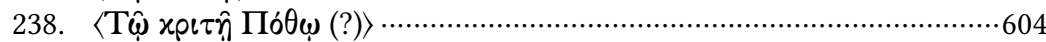

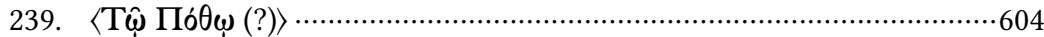

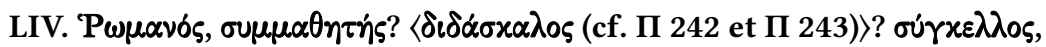
$\mu \eta \tau \rho о \pi 0 \lambda i \tau \eta \zeta ~ K u \zeta i$ ixou (ca. a. 1064 - a. 1079?)

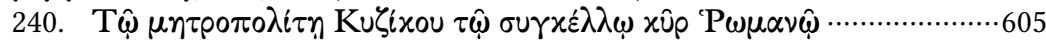

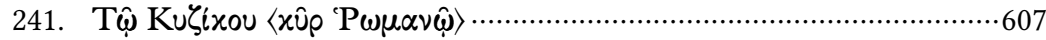

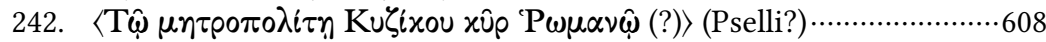

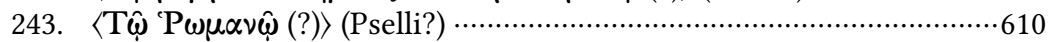

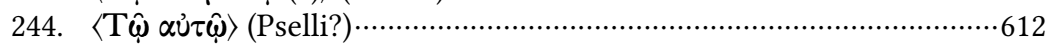

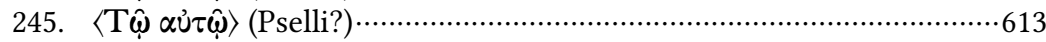

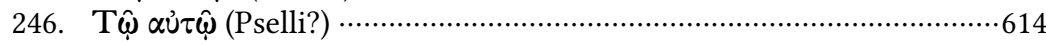

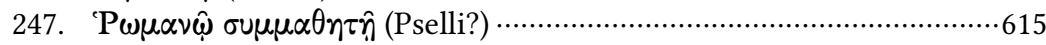

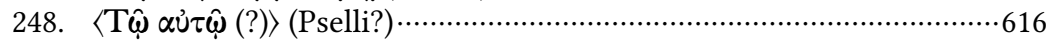

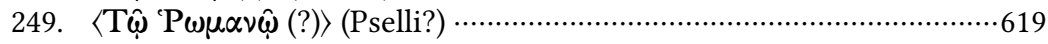

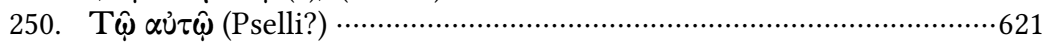

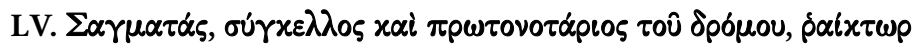

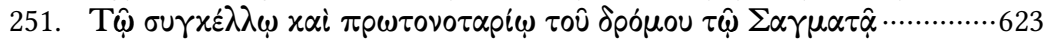

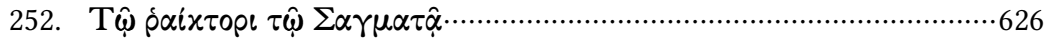

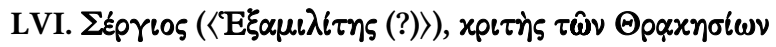

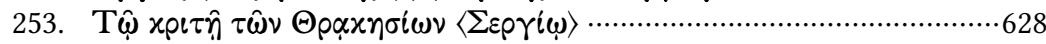

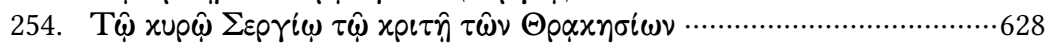




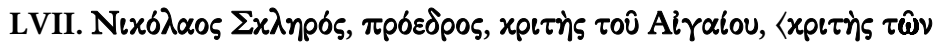

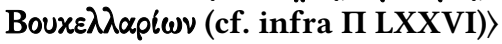

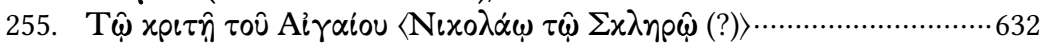

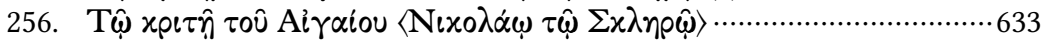

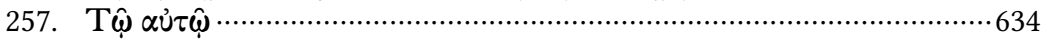

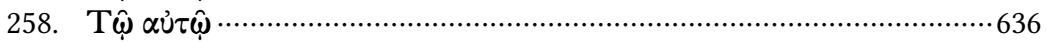

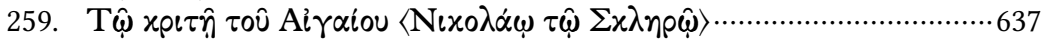

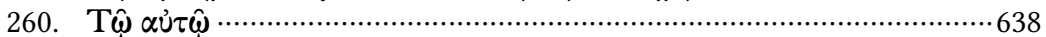

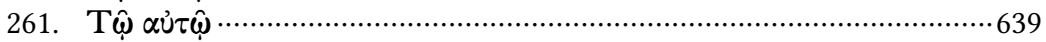

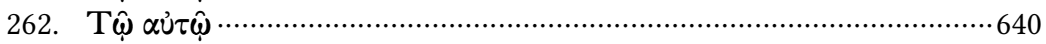

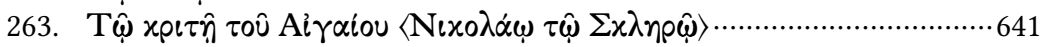

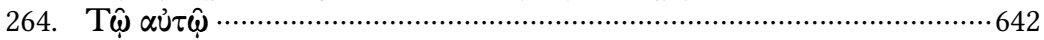

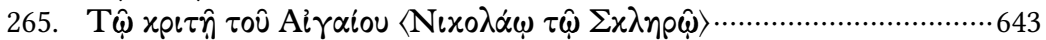

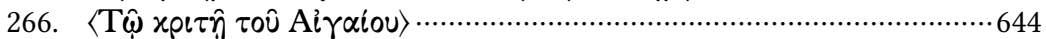

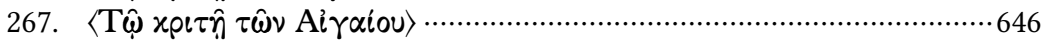

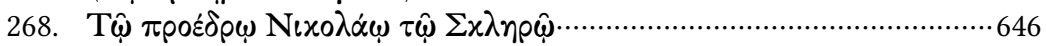

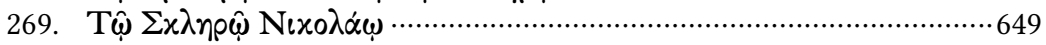

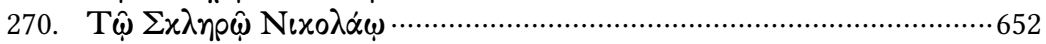

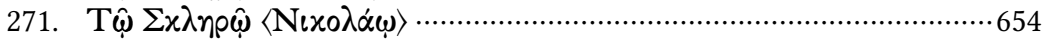

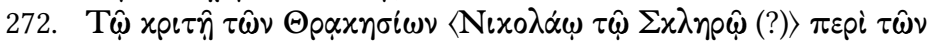

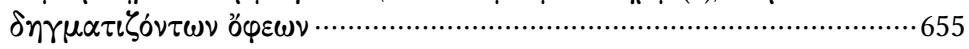

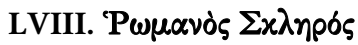

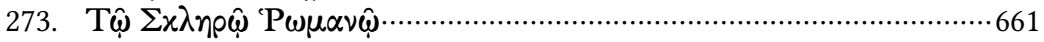

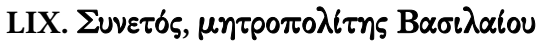

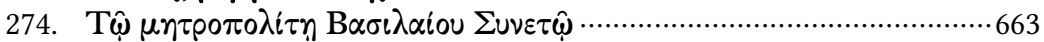

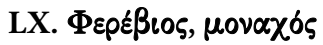

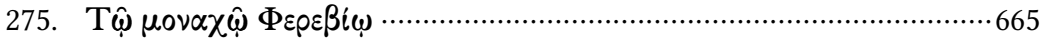

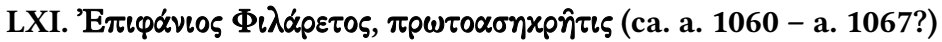

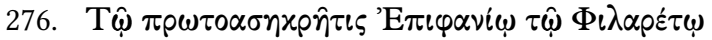

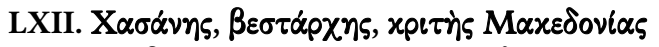

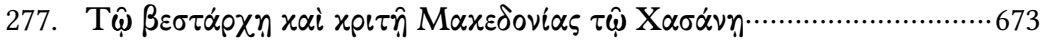

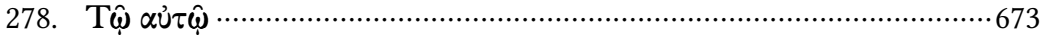

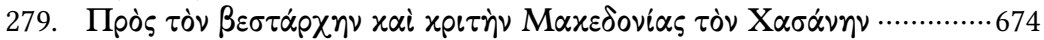

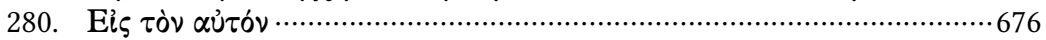

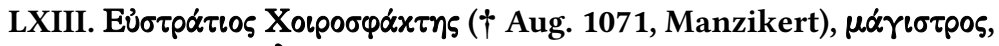

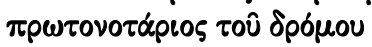

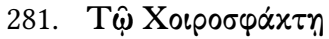




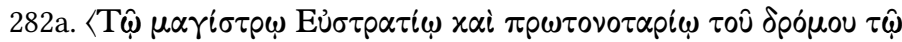

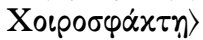

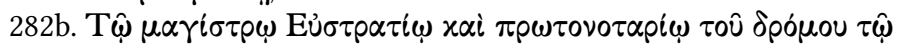

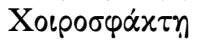

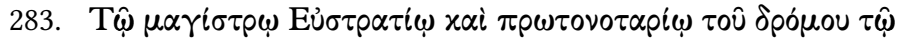

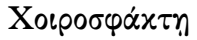

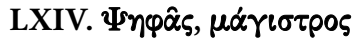

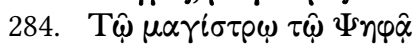

285. T⿳亠丷厂 $\alpha \dot{\tau} \tau \hat{\varphi}$

LXV. A A

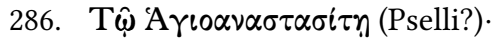

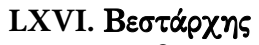

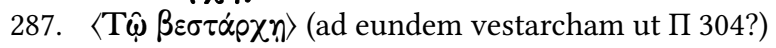

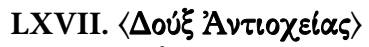

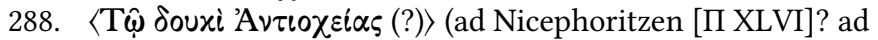
Ioannem Ducam [П XVII]?)

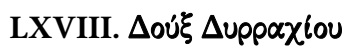

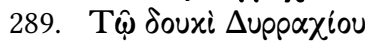

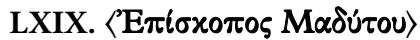

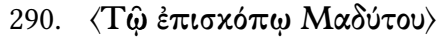

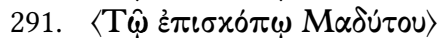

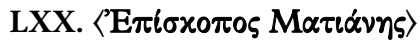

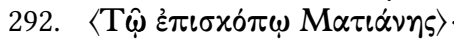

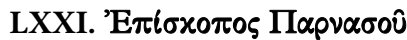

293. Тழ̣̂ ह่ $\pi \iota \sigma x o ́ \pi \omega ~ \Pi \propto \rho \nu \alpha \sigma o \hat{~}$

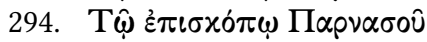

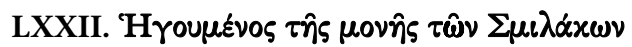

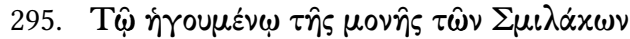

LXXIII. Koupá $\tau \omega \rho$ Kútрou

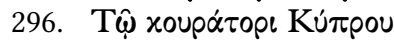

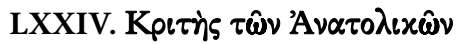

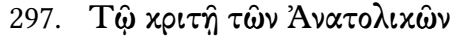

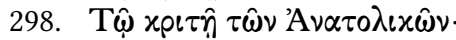




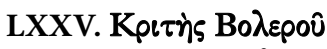

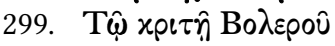

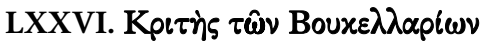

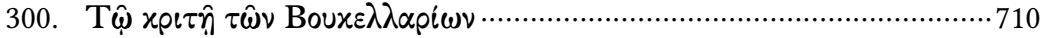

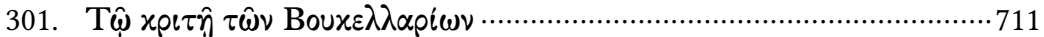

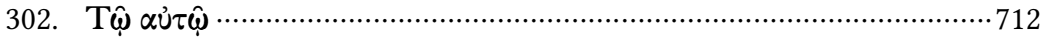

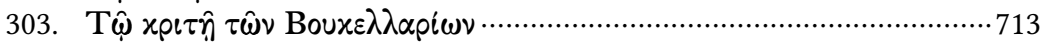

LXXVII. Koı

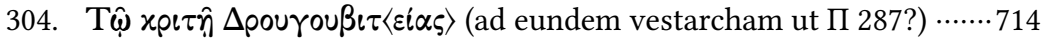

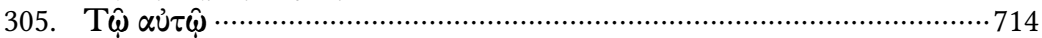

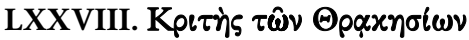

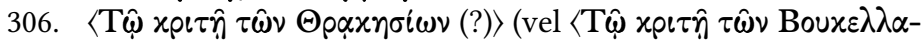

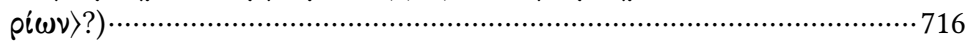

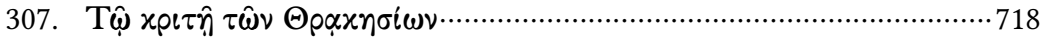

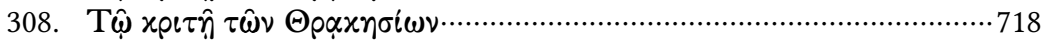

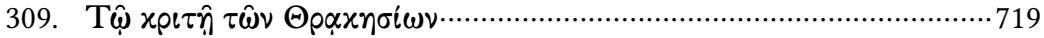

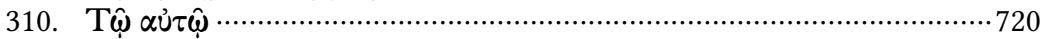

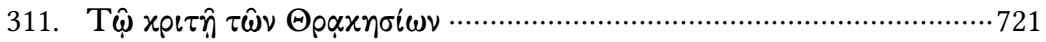

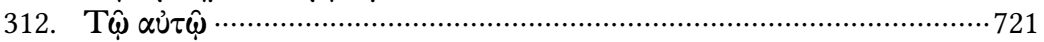

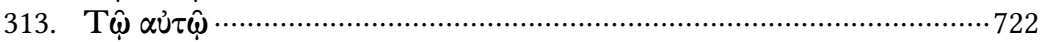

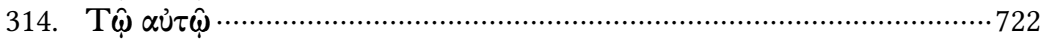

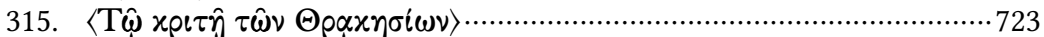

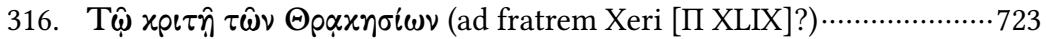

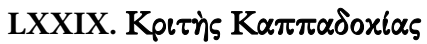

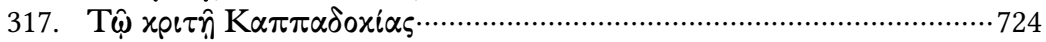

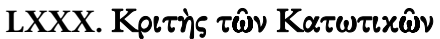

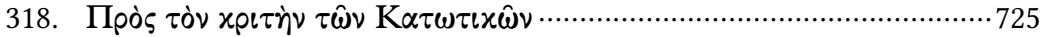

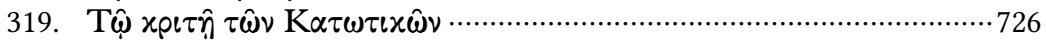

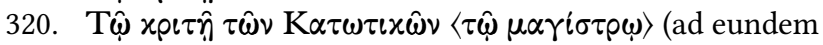

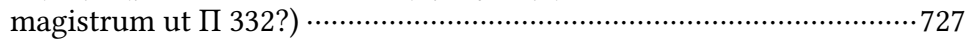

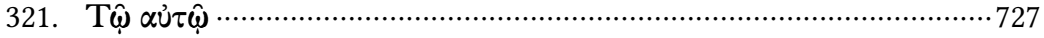

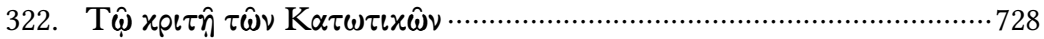

323.

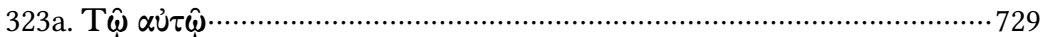

323b. (versio altera [retractatio?] in cod. $\mathrm{v}^{1}$ ) …...................................... 730

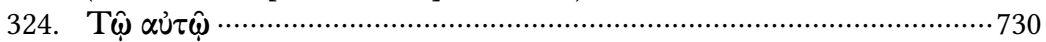

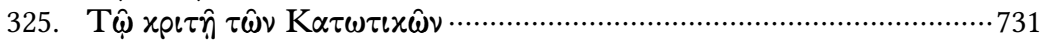

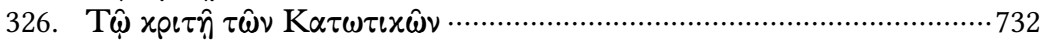

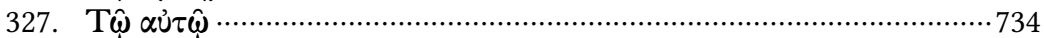

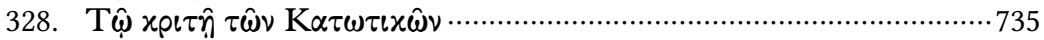




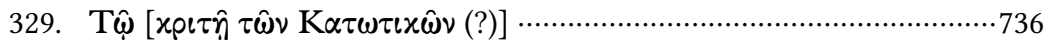

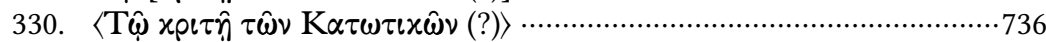

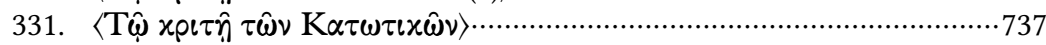

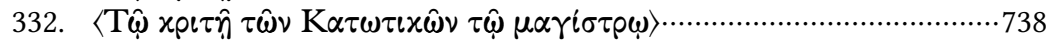

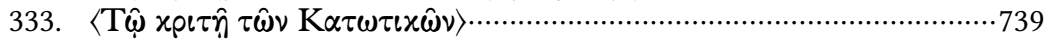

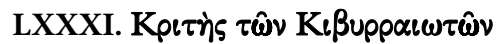

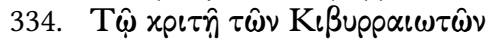

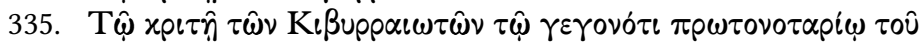
$\delta \rho o ́ p o u$

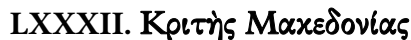

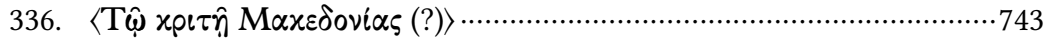

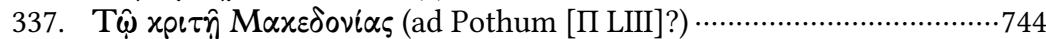

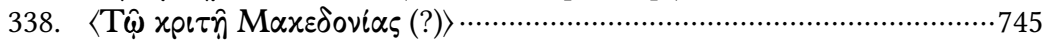

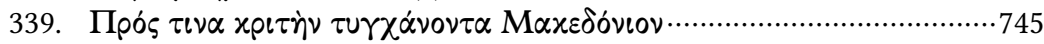

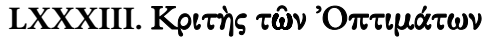

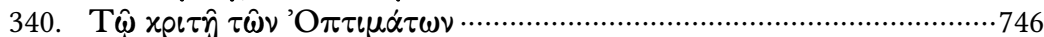

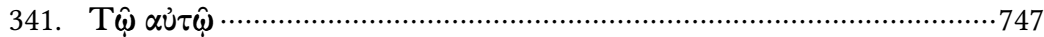

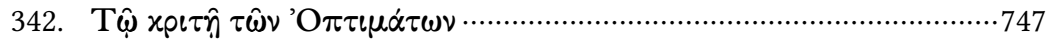

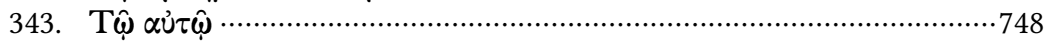

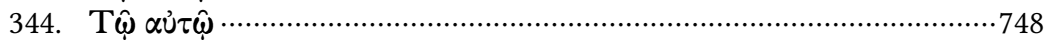

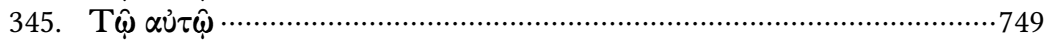

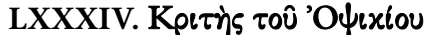

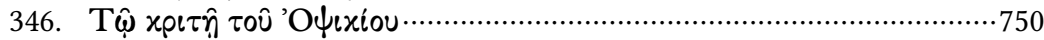

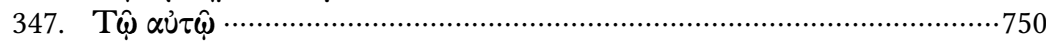

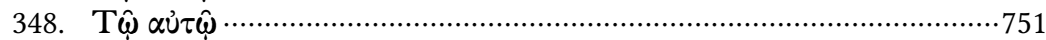

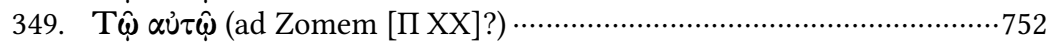

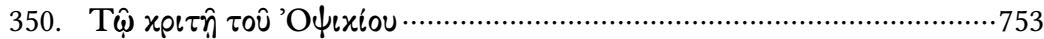

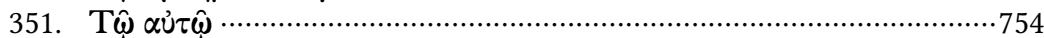

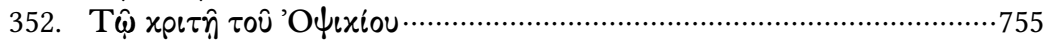

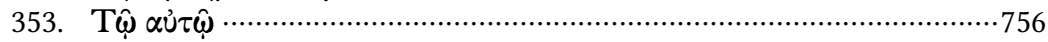

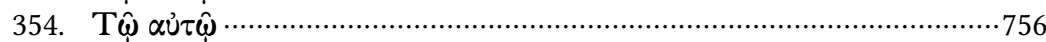

355.

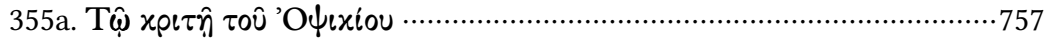

355b. (versio altera [retractatio?], in cod. A)…...........................................759

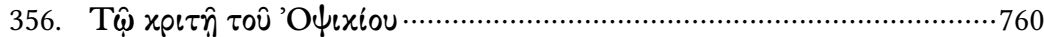

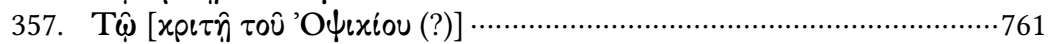

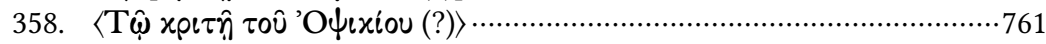

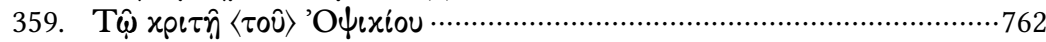

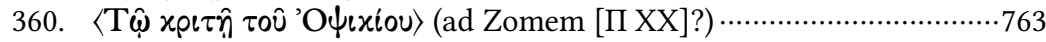

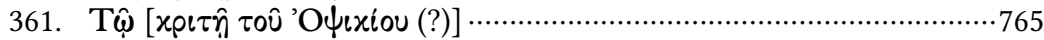




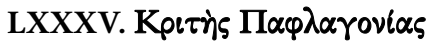

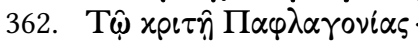

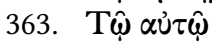

364.

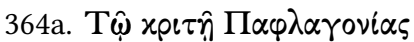

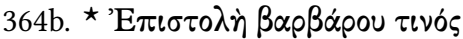

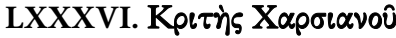

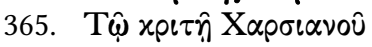

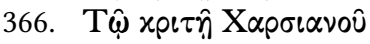

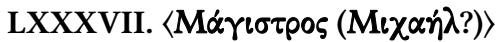

367. $\left\langle\mathrm{T} \hat{\varphi} \mu \alpha \gamma^{i} \sigma \tau \rho \omega\left(\mathrm{M} \iota \chi \alpha \hat{\eta}^{\prime} \lambda\right.\right.$ ? $\left.)\right\rangle$

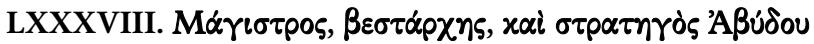

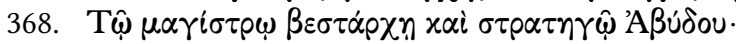

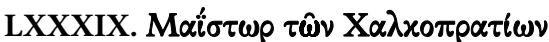

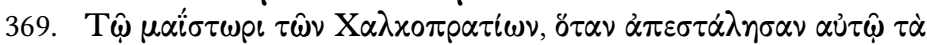

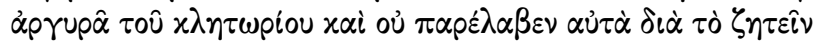
$\pi \lambda$ ciov $\alpha$

XC. MÉras oỉxovónos

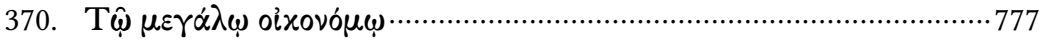

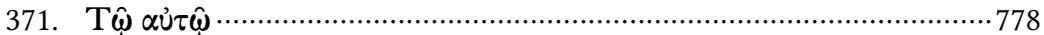

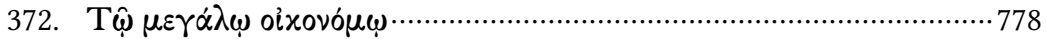

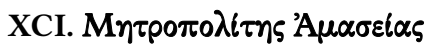

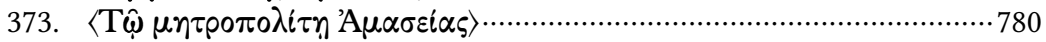

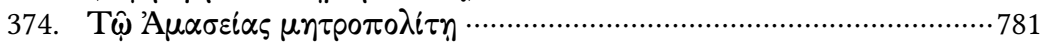

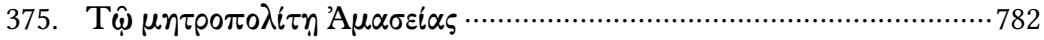

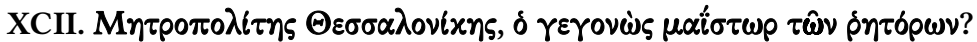

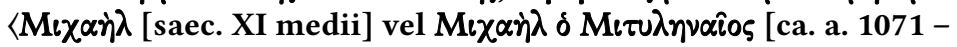
a. 1079](?)〉

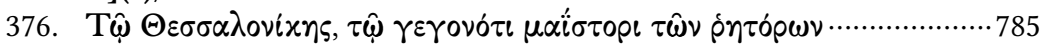

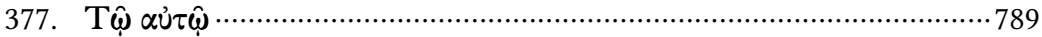

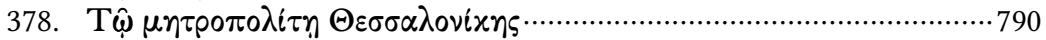

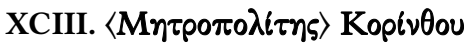

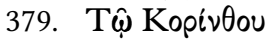

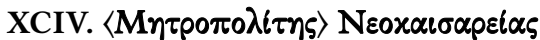

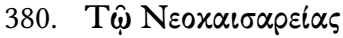




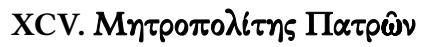

381. Т⿳⺈ $\mu \eta \tau \rho \circ \pi \circ \lambda i \tau \eta \Pi \alpha \tau \rho \hat{\omega} \nu$

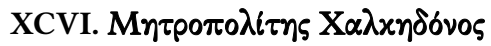

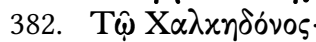

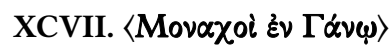

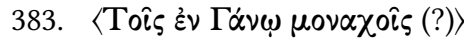

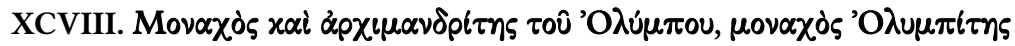

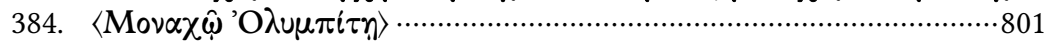

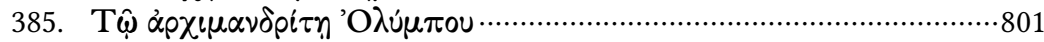

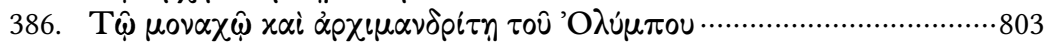

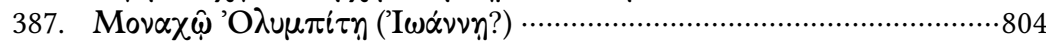

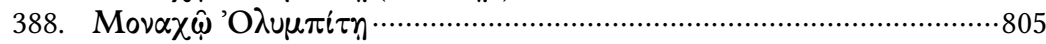

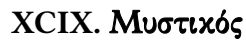

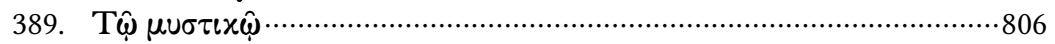

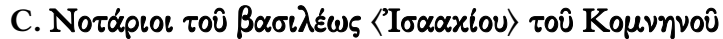

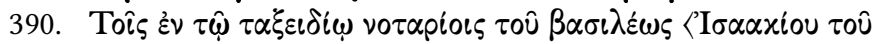

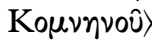

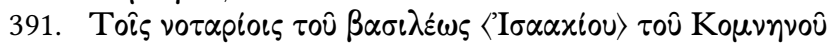

CI. 'O

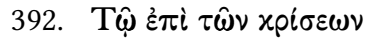

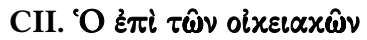

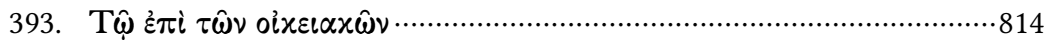

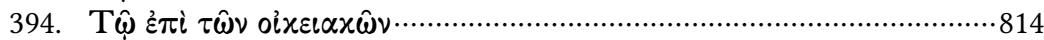

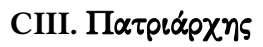

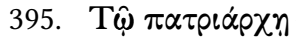

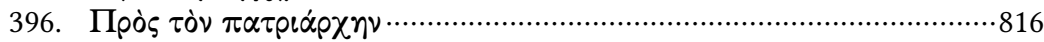

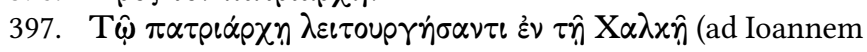

Xiphilinum $[\Pi \mathrm{L}]$ ?) ……………………………………………….

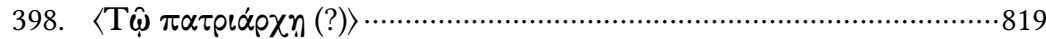

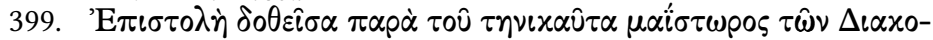

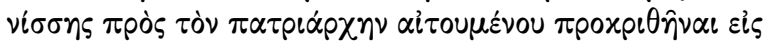

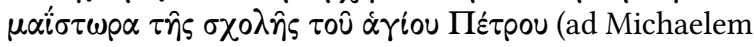
Cerularium [П XXIX]? ad Constantinum Leichouden $(\Pi$ $\mathrm{XXXV}]$ )

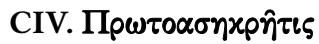

400. $\langle\mathrm{T} \hat{\varphi} \bar{\pi} \pi \omega \tau \sigma \alpha \sigma \eta \times \rho \hat{\tau} \tau \iota \zeta\rangle$ 


\section{Ad incertas personas}

401. 824

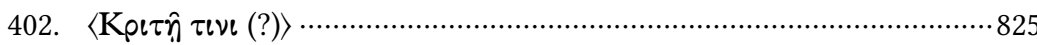

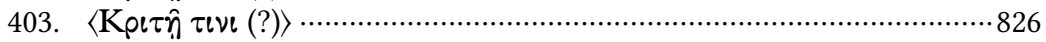

404. 'A $\nu \varepsilon \pi i\} \rho \alpha \varphi \circ \varsigma$ (ad kriten quendam [cf. П 260]?) ……........................826

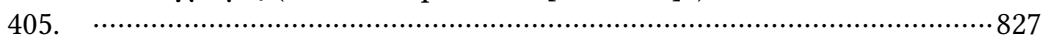

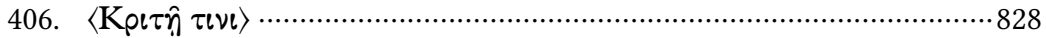

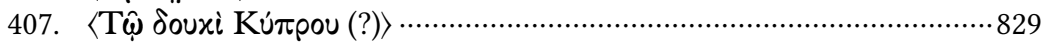

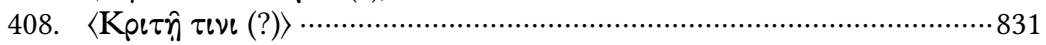

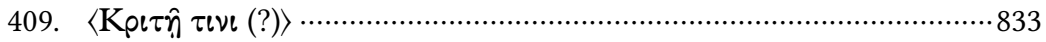

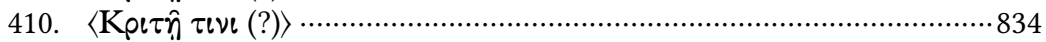

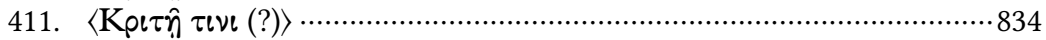

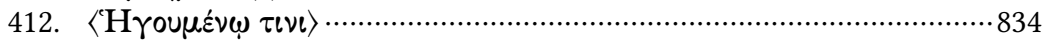

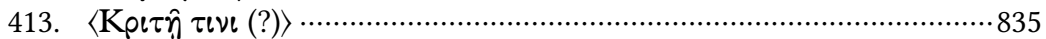

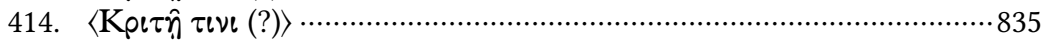

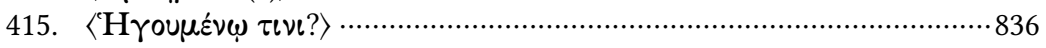

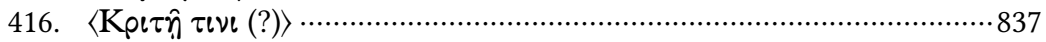

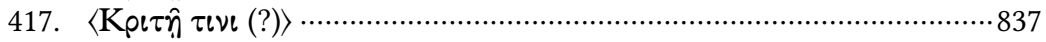

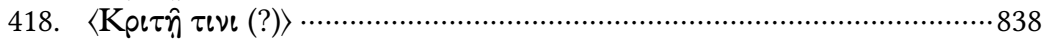

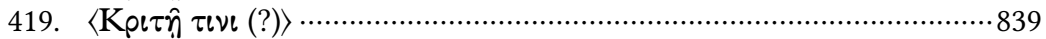

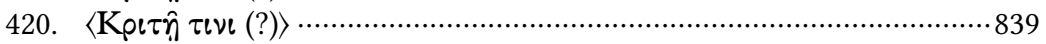

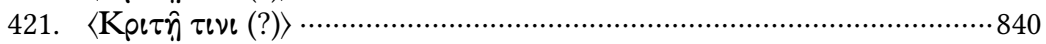

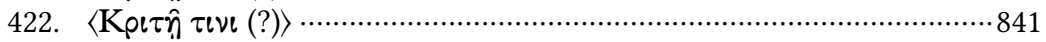

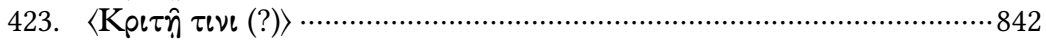

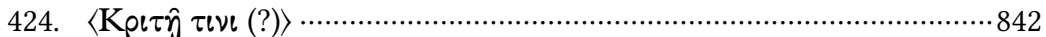

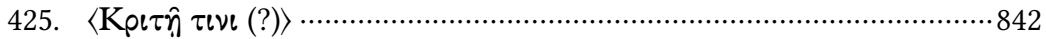

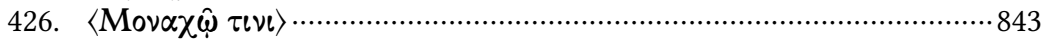

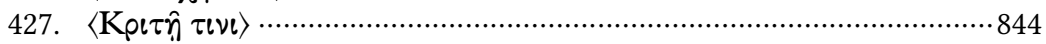

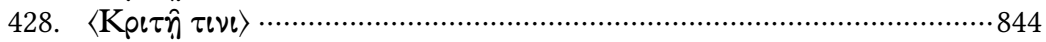

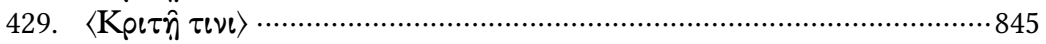

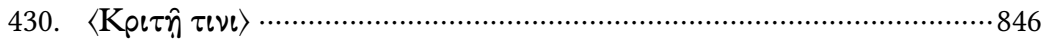

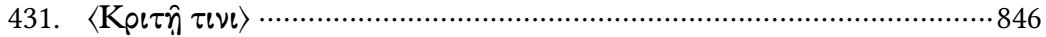

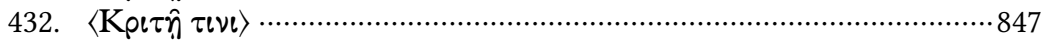

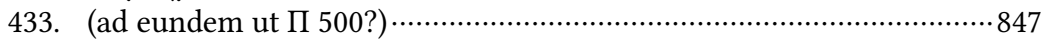

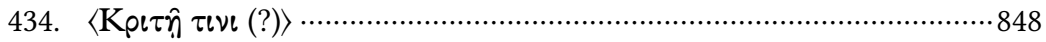

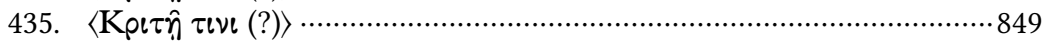

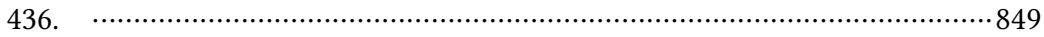

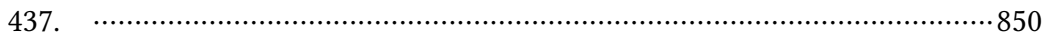

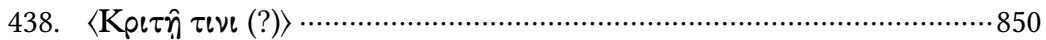

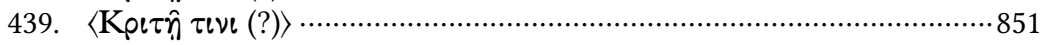

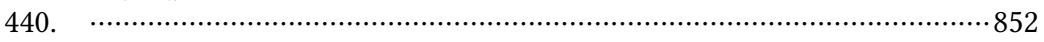

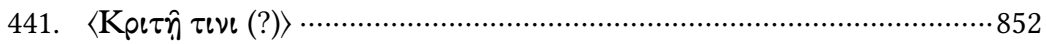

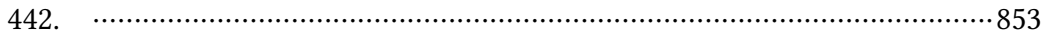

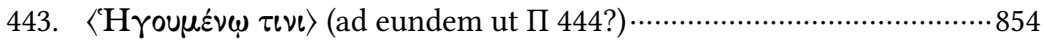


444. [ca. 6 litt.?] $\mu$ ov $\propto \chi \hat{\varphi}$ (ad eundem ut $\Pi 443$ ? ad Ioannem Xiphilinum [ח L]?)

445. (Pselli?)

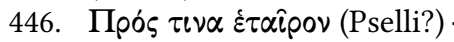

447.

447a. (Pselli?)

447b. * (versio altera [retractatio?] in collectione epistolarum Hierothei monachi)

448.

448a. (Pselli?)

448b. * (versio altera [retractatio?] in collectione epistolarum

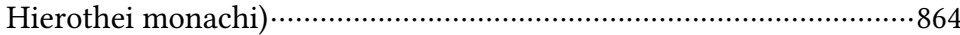

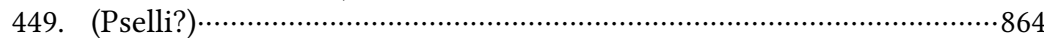

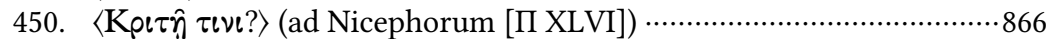

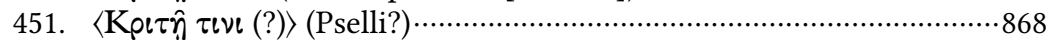

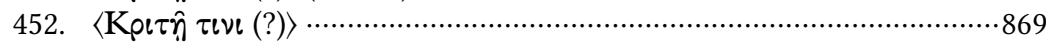

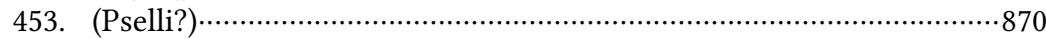

454.

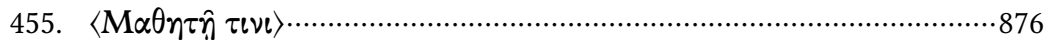

456. T $\hat{\varphi}$ [ca. 15 litt.] (ad kriten quendam) …............................................ 878

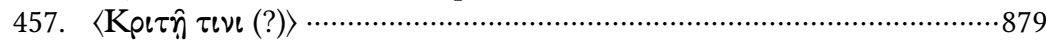

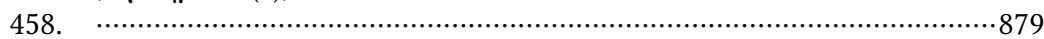

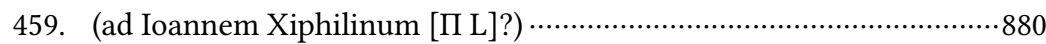

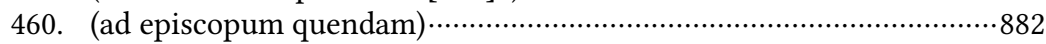

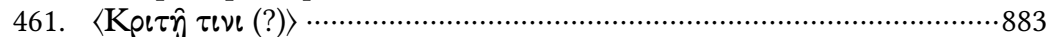

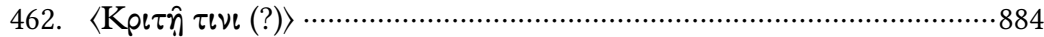

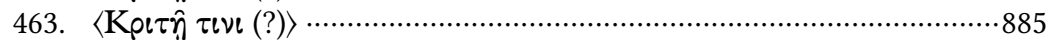

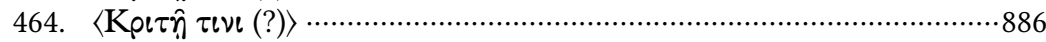

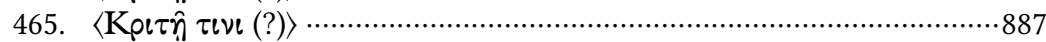

466. T⿳⺈ [ca. 15 litt.] (ad kriten quendam? ad logotheten tou dromou quendam?) …............................................................................. 889

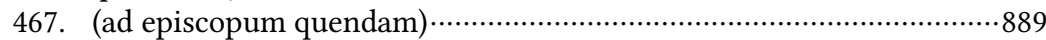

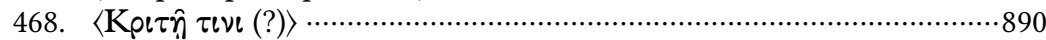

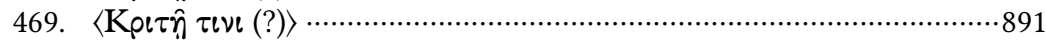

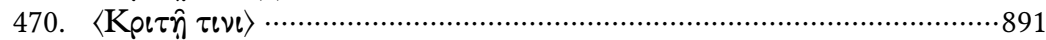

471. 〈K

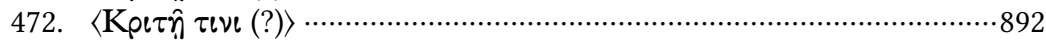

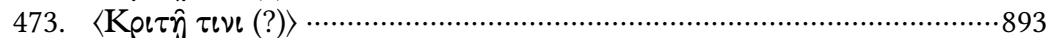

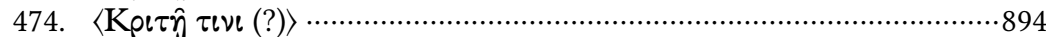

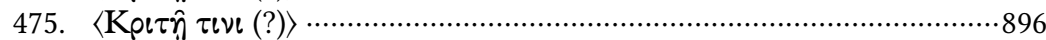

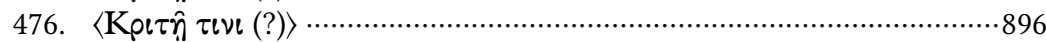

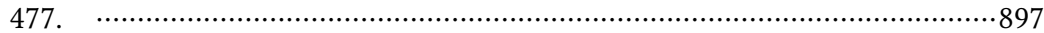

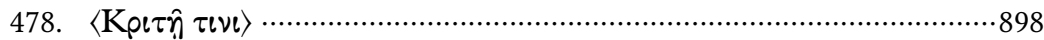

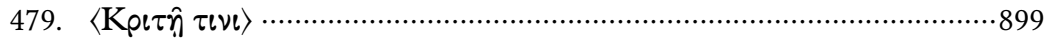

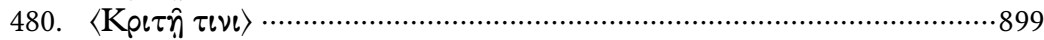




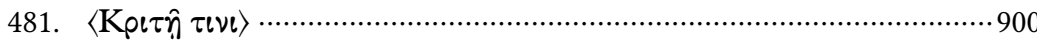

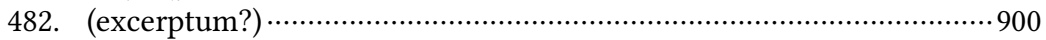

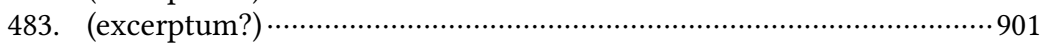

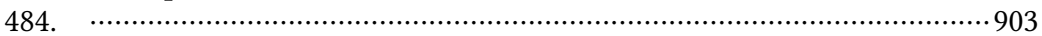

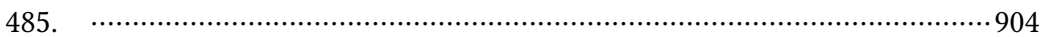

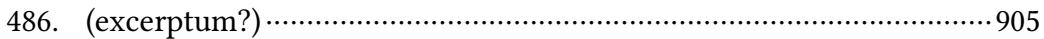

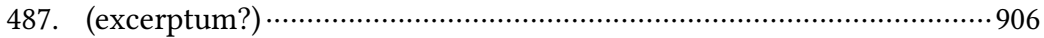

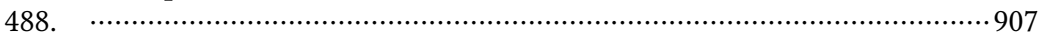

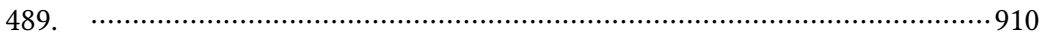

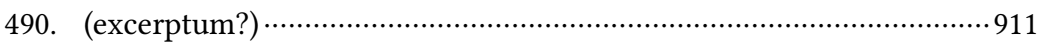

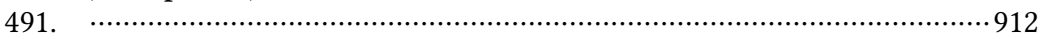

492. (ad Ioannem Ducam [П XVII] vel ad Constantinum, nepotem Michaelis Cerularii $[\Pi \mathrm{XXX]}$ ?) …................................................ 913

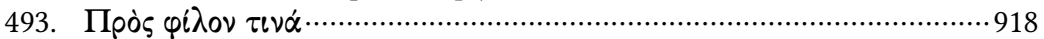

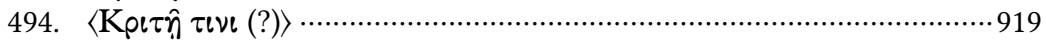

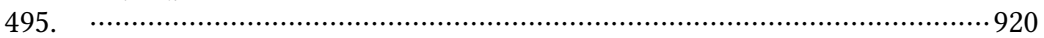

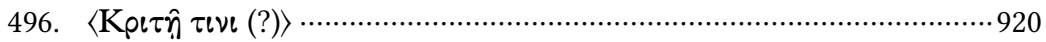

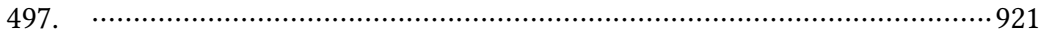

498. (ad Ioannem Mauropoda [П ХХХІХ]?) …….................................. 923

499.

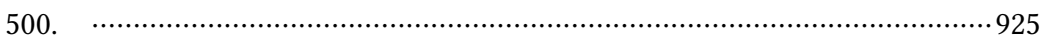

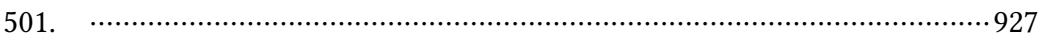

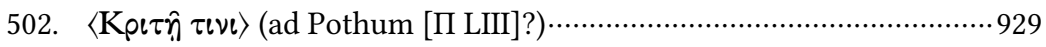

503. (ad episcopum quendam?) …………........................................ 929

504. (ad unum amicorum eius in Cappadocia militiis ab Romano IV Diogene inceptis) …............................................................... 930

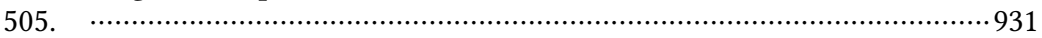

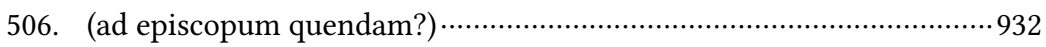

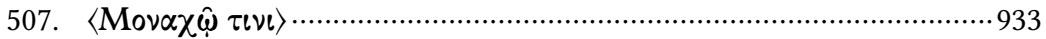

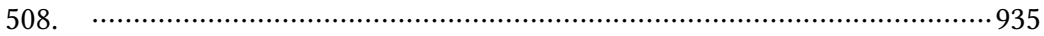

509.

510.

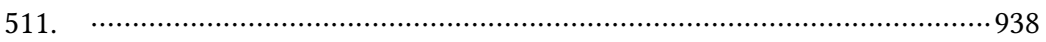

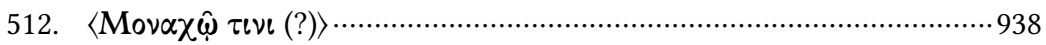

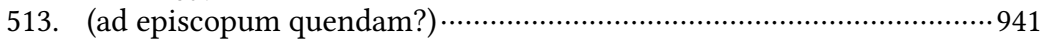

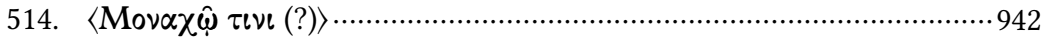

515. (ad episcopum quendam) ………................................................... 943

516. (ad Ioannem Mauropoda [П XXXIX]? ad Ioannem Xiphilinum

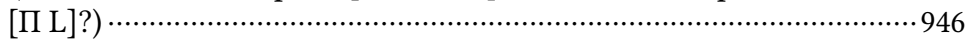

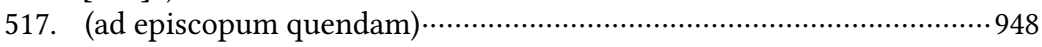

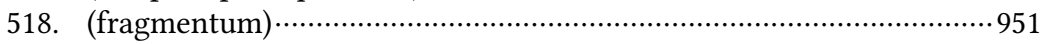

Dubia, incerta, excerpta, sententiae, retractationes, et epistulae aliorum auctorum in collectione pselli preservatae

519. (ex Pselli scriptis?) 
520. (ex Pselli scriptis?)

521. (excerpta de appellationibus [ex П 379 (ll. 1-2) et $\Pi 374$ (ll. $1-3)])$

522. (sententia; ex Pselli scriptis?) ……............................................... 954

523. (sententia; ex Pselli scriptis?) ……................................................ 954

524. (excerptum; ex Pselli scriptis?) ……............................................... 954

525. (excerptum; ex Pselli scriptis?) ……............................................... 955

526. (excerptum; ex Pselli scriptis?) ……................................................. 955

527. (excerptum; ex Pselli scriptis?) ……..............................................956

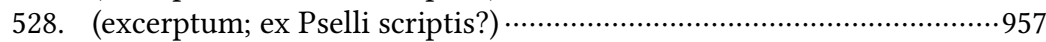

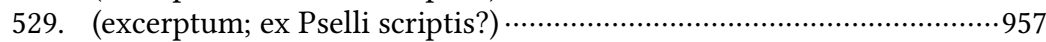

530. (excerptum; ex Pselli scriptis?) ……............................................... 958

531. (excerptum; ex Pselli scriptis?) ……............................................... 958

532. (excerptum; ex Pselli scriptis?) …….................................................958

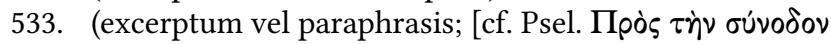

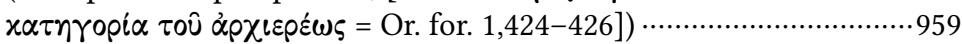

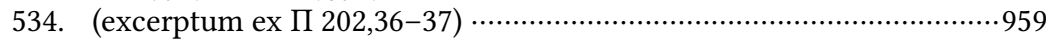

535. (excerptum ex $\Pi$ 202,105-106) ……..............................................959

536. (excerptum ex $\Pi$ 377,12-18 et excerptum aliud) …............................960

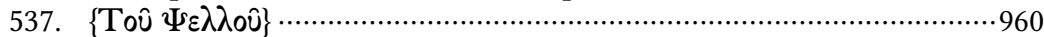

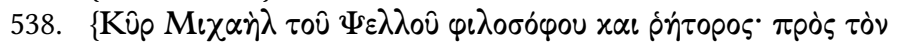

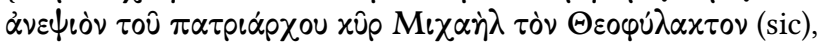

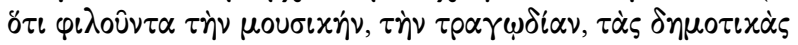

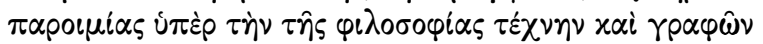

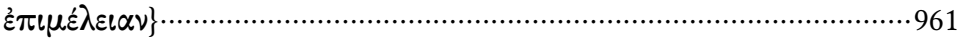

539.

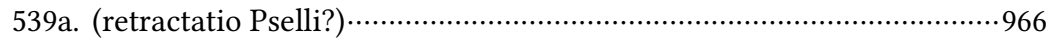

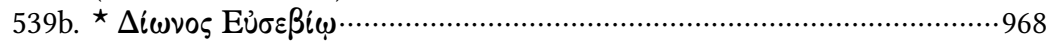

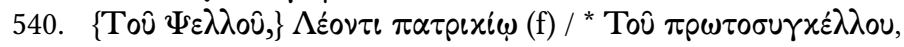

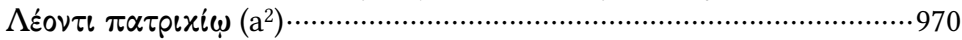

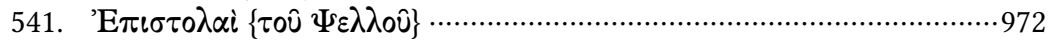

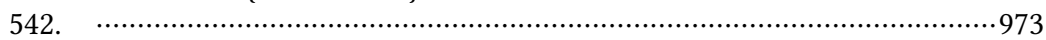

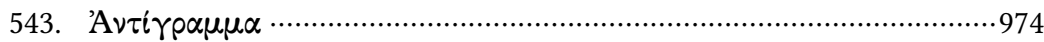

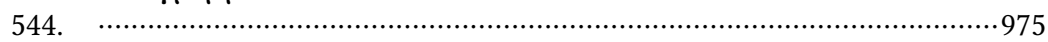

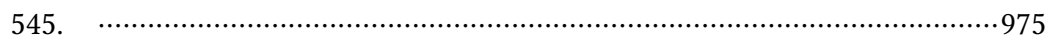

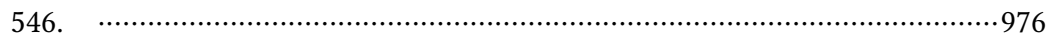

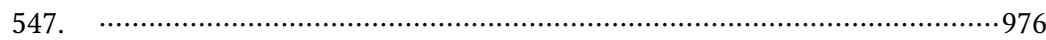

548. (Euthymii Malace?) …….................................................................. 977

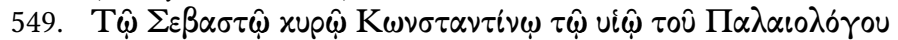

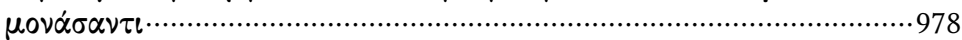

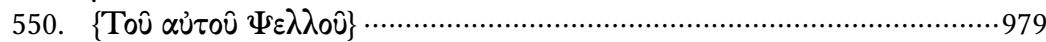

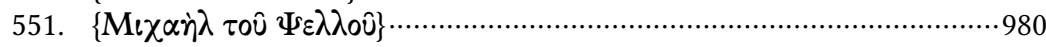

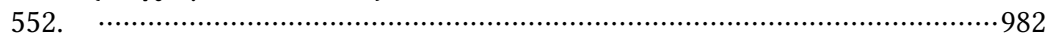

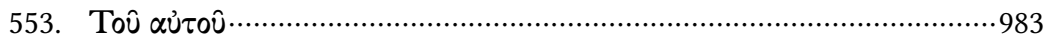

554. 


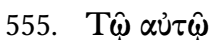

556.

\section{Indices}

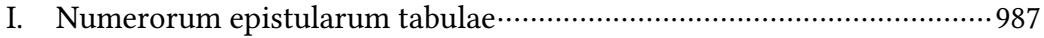

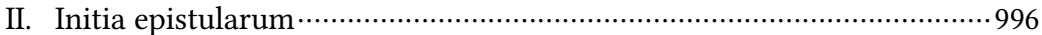

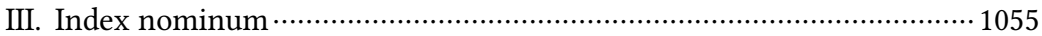

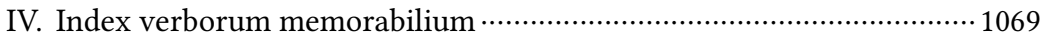

V. Index locorum

1) Citations, acknowledged or tacitly embedded .................................... 1073

2) Likely references, allusions, and parallel

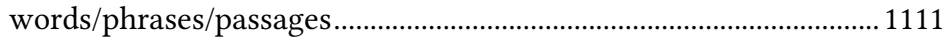

3) Uncertain references and allusions .................................................... 1187

4) Common places / phrases....................................................................1189

5) Words, short locutions, or concepts that are fairly common in / typical of / or derive specifically from an author or type of

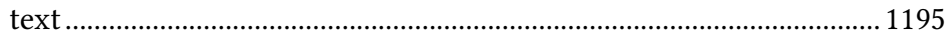

6) Possible allusions to Psellian words or phrases in post-Psellian authors 
